Article

\title{
Propagation of Pistacia lentiscus var. Chia Genotypes and Determination of Their Ornamental Traits Combined with a Genetic Analysis Using ISSR Markers
}

\author{
Stefanos Kostas ${ }^{1, *(\mathbb{D})}$, Stefanos Hatzilazarou ${ }^{1}$ (D), Elias Pipinis ${ }^{2}$, Anastasios Vasileiadis ${ }^{3}$ (D), Panagiotis Magklaras ${ }^{3}$, \\ Ilias Smyrnioudis ${ }^{4}$, , Tilemachos Vasilakis ${ }^{4}$, Michalis Chazakis ${ }^{4}$, Vasiliki Anastasiadi ${ }^{1}$, \\ Fotios-Theocharis Ziogou ${ }^{1}$, Aikaterini Kotoula ${ }^{1}$, Amalia-Sofia Afendra ${ }^{3}$, Efstathios Hatziloukas ${ }^{3}$ \\ and Athanasios Economou ${ }^{1}$
}

check for updates

Citation: Kostas, S.; Hatzilazarou, S.; Pipinis, E.; Vasileiadis, A.; Magklaras, P.; Smyrnioudis, I.; Vasilakis, T.; Chazakis, M.; Anastasiadi, V.; Ziogou, F.-T.; et al. Propagation of Pistacia lentiscus var. Chia Genotypes and Determination of Their Ornamental Traits Combined with a Genetic Analysis Using ISSR Markers. Agronomy 2021, 11, 205. https://doi. org/10.3390/agronomy11020205

Received: 8 December 2020

Accepted: 19 January 2021

Published: 22 January 2021

Publisher's Note: MDPI stays neutral with regard to jurisdictional claims in published maps and institutional affiliations.

Copyright: (c) 2021 by the authors. Licensee MDPI, Basel, Switzerland. This article is an open access article distributed under the terms and conditions of the Creative Commons Attribution (CC BY) license (https:/ / creativecommons.org/licenses/by/ $4.0 /)$.
1 Department of Horticulture, School of Agriculture, Aristotle University, 54124 Thessaloniki, Greece; hatzilaz@agro.auth.gr (S.H.); vasilanast@agro.auth.gr (V.A.); fotiziog@agro.auth.gr (F.-T.Z.); kotoulaa@agro.auth.gr (A.K.); aseconom@agro.auth.gr (A.E.)

2 Laboratory of Silviculture, School of Forestry and Natural Environment, Aristotle University, 54124 Thessaloniki, Greece; epipinis@for.auth.gr

3 Laboratory of Molecular Biology and Genetics, Department of Biological Applications and Technologies, University of Ioannina, 45110 Ioannina, Greece; avasilei@uoi.gr (A.V.); panosmag80@yahoo.gr (P.M.); aafendra@uoi.gr (A.-S.A.); ehatzilu@uoi.gr (E.H.)

4 Chios Mastic Gum Growers Association, 1 K. Monomachou St., 82100 Chios, Greece; ismyrnioudis@gummastic.gr (I.S.); tvasilakis@gummastic.gr (T.V.); mxazakhs151@gmail.com (M.C.)

* Correspondence: skostas@agro.auth.gr; Tel.: +30-2310-991775

Abstract: Pistacia lentiscus L. is a dioecious shrub or small tree with high drought resistance, native in the entire Mediterranean basin. The variety 'Chia' (mastic tree) is cultivated for the production of mastic gum (a resin produced after wounding of the trunks and thick branches) in the Island of Chios (Greece), but it also has a significant ornamental value. In the present study, ten male and ten female genotypes of $P$. lentiscus var. Chia from the natural habitats of Chios were selected and examined with respect to the rooting efficiency of their shoot cuttings. The germination ability of the seeds was also tested. The 20 plants were morphologically described, mainly with respect to traits related to their ornamental value. Furthermore, leaves were collected from the 20 genotypes, from which genomic DNA (gDNA) was isolated, followed by amplification of gDNA fragments using the polymerase chain reaction (PCR) and inter simple sequence repeat (ISSR) primers. This was done aiming both at the determination of their genetic distance and the establishment of possible correlations between the amplified bands and certain morphological traits. The results of the study showed that there were differences among the genotypes for both methods of propagation. Regarding the rooting of the shoot cuttings, the best genotype was $8 \mathrm{M}$ (cv. 'Psilophyllos'), achieving a rooting rate of $62.5 \%$ in winter with the application of indolebutyric acid (potassium salt of IBA), while regarding the seed germination capacity the genotype $2 \mathrm{~F}$ exhibited the highest germination rate $(57 \%)$. Genetic analysis using ISSRs separated the plants into four groups, one group consisting of male genotypes, one of the female genotypes, one consisting of members from both genders and a fourth containing a single male genotype. The genetic analysis of the male genotypes only produced a dendrogram showing the cultivars clustering in three different groups. Regardless of the genetic analysis, it seems that there were correlations between the ISSR markers and the leaf traits and also the gender and the asexual propagation. These correlations can assist future breeding programs of P. lentiscus var. Chia.

Keywords: mastic tree; K-IBA; molecular markers; morphological traits; rooting; scarification; seed germination; vegetative propagation 


\section{Introduction}

The genus Pistacia (Anacardiaceae) comprises nine species and five subspecies [1]. The members of the genus are dioecious evergreen or deciduous and resin-bearing shrubs or small trees, which are characterized as xerophytic species [2]. Pistacia lentiscus L. (known as lentisk) is one of the most characteristic component of the maquis communities in the Mediterranean basin [3]. It is an evergreen shrub, 2-3 $\mathrm{m}$ in height, or sometimes a small tree up to 3-4 $\mathrm{m}$ in height.

On the Chios Island of Greece, an economically important variety of P. lentiscus named 'Chia' (known as the mastic tree) is cultivated and, according to Browicz [4], differs from the wild species due to its tree-like growth. The P. lentiscus L. var. Chia trees, which secrete a substance of resin composition, known locally as "mastiha", are cultivated by farmers in dry and warm environments in the southern part of Chios. "Mastiha" is collected, traded and exploited under the "Chios Mastic Gum Growers Association" supervision. It is a dry resinous secondary metabolite produced as a reaction of the plant to wounding (or "kentima" as it is called on Chios) of stems and thick branches. "Mastiha", which is traditionally used in confectionery and perfumery, contains a variety of bioactive phytochemicals and also has been scientifically proven that it has important medicinal properties $[5,6]$.

P. lentiscus var. Chia, with dark-green dense, leathery foliage, is highly resistant to water stress and salinity $[7,8]$ and, thus, can be a suitable landscaping choice in the arid and semi-arid environments of the Mediterranean basin, even in the urban residential landscapes. The female plants have an extra valuable trait, which is red to dark-red fruits contrasting to green foliage, a very interesting feature well known by artists of floral arrangements [9]. Thus, with such morphological characteristics and ecophysiological properties, the mastic tree could be introduced into production for ornamental use. In this case, an efficient propagation protocol of selected genotypes with desirable ornamental traits is the first step for the introduction of this species into horticultural practice.

The mode of propagation of $P$. lentiscus in nature occurs through seed germination. For many species, propagation from seeds is the most common and the cheapest method used in nurseries [10]. As a further benefit, seed propagation promotes genetic diversity, which constitutes the basis for the creation of new varieties. Despite the fact that this procedure is simple, seed dormancy is one of the biggest hurdles that must be overcome and often is a challenge for the propagator. In the relevant literature, there is conflicting information regarding the dormancy of P. lentiscus seeds. According to Piotto et al. [11], the seeds of $P$. lentiscus are surrounded by a hard endocarp that may reduce the rate of imbibition and, thus, the germination process. For this reason, they proposed mechanical scarification or, alternatively, a short period of cold stratification of seeds as an auxiliary method to overcome this dormancy. However, in a previous report, Piotto [12] stated that the treatment of $P$. lentiscus seeds with scarification or cold stratification increases the speed of the germination process significantly but does not affect the final germination percentage. On the other hand, Abu-Qaoud [13] concluded that the scarification treatment, followed by cold stratification or gibberellic acid $\left(\mathrm{GA}_{3}\right)$ application, significantly improved the germination percentages, as well as the speed of the germination of P. lentiscus seeds. In contrast with the previous references, Garcia-Fayos and Verdu [14], as well as Isfendiyaroglu [15], stated that the seeds of $P$. lentiscus did not exhibit any dormancy and, consequently, no treatment was needed. They concluded that pulp removal was the only necessary treatment for a successful germination event. Mulas et al. [16] found significant differences among 33 female genotypes of $P$. lentiscus, which were related to the length of two-year-old shoot, fruit number per branch, fruit and seed size, germination percentage and speed of germination. Taking into account this information, the selection of genotypes producing a high percentage of viable seeds and the application of necessary treatments will be useful for the production of P. lentiscus plants in a nursery.

Propagation by seeds cannot be applied when high homogeneity of the produced plants is required. For this reason, it would be advisable the selection of suitable genotypes 
of high propagation capacity through cuttings and also the improvement of the asexual propagation methods used. Traditionally, the mastic trees are propagated vegetatively by hardwood shoot cuttings, which are planted directly to the soil where the tree plantation will be established [4]. However, according to Joley and Opitz [17], the rooting of shoot cuttings of $P$. lentiscus is considered very difficult. The successful rooting of shoot cuttings is affected by several factors, which could be divided into two general categories: those occurring before the removal of shoot cuttings from the mother plant (pre-removal) and those occurring afterward (post-removal) [10]. In an effort to improve the rooting capacity of mastic tree shoot cuttings, various treatments were used. According to Kostas et al. [18], the plant genotype, the application of potassium salt of indolebutyric acid (K-IBA), the rooting substrate and the season of cuttings collection significantly influenced the adventitious root formation of the mastic tree shoot cuttings. In addition, it was found that winter was the proper season for shoot cutting collection [18].

There is limited work regarding the classification of P. lentiscus var. Chia. Thus, much effort should be put into this by using ISSR molecular markers, which are considered the most suitable for genetic identification when intraspecific genetic variations are studied. There is only one report concerning plant material originating from the Island of Chios, while two other reports refer to genotypes from Turkey. Zografou et al. [19] investigated the genetic diversity of ten genotypes derived from Chios, using random amplified polymorphic DNA (RAPD) and ISSR molecular markers. They concluded that the cultivars 'Mavroschinos' and 'Votomos' are closer genetically, although their data show clearly that members of 'Mavroschinos' are genetically heterogeneous. In addition, they concluded that the cultivar 'Maroulitis' is distinct from both 'Mavroschinos' and 'Votomos'. In addition, a female tree was grouped separately from the male genotypes [19]. In another work, Abuduli et al. [20], using more molecular markers [ISSR, simple sequence repeat (SSR), RAPD and internal transcribed spacer (ITS)], separated genetically 24 genotypes of $P$. lentiscus from Turkey (including only one genotype from Chios, Greece). The results indicated that the male and female genotypes were distinctly separated from each other and that the ISSR markers were suitable for the analysis of intraspecific variations of $P$. lentiscus trees. In a recent study, carried out on P. lentiscus in Turkey [21], ISSR and inter retrotransposon amplified polymorphism (IRAP) markers were used to evaluate the intraspecific variation and phylogenetic relationships in 31 native genotypes (including one from Chios and one from Crete, Greece). The results showed that the 31 P. lentiscus genotypes were segregated on three different main clusters and that there exhibited very high ratios of intraspecific variation. In addition, Kafkas and Perl-Treves [22] and Kafkas [23] reported taxonomical relations of Turkish Pistacia species based on RAPD and amplified fragment length polymorphism (AFLP) markers, respectively.

The aim of the present study was to select genotypes of $P$. lentiscus var. Chia for ornamental use. For this purpose, genetic analyses and biometric measurements of the selected individuals were used. The ability to reproduce plants from shoot cuttings and/or seeds was also investigated. Furthermore, this study aimed to identify correlations existing between morphological traits and ISSR markers for exploiting those in future breeding programs.

\section{Materials and Methods}

\subsection{Plant Material}

Twenty genotypes of P. lentiscus var. Chia from Chios Island were selected based on the criteria of their morphology (appearance) and their ornamental value (such as the good shape of the plant, the rich and dense canopy, the size of the leaves, etc.) and also their geographical location in the area of Southern Chios. The plants were grown in various natural habitats, far from each other, with the purpose of achieving a representative distribution over a wider geographical range. The names of the regions of the selected genotypes, as well as their geographical locations, are presented in Table 1 and Supplementary Figure S1. The selected plant material included ten male and ten female trees. The male trees are more productive in mastic gum and, thus, are preferable for cultivation by the mastic growers 
of Chios, whereas the female trees are less productive and usually are not cultivated. In addition, for the selection of the ten male trees, their classification into five main local cultivars (two plants per cultivar) was taken into consideration. The names of the selected cultivars were 'Mavroschinos' (MV), 'Psilophyllos' (PS), 'Maroulitis' (ML), 'Platiphyllos' (PL) and 'Votomos' (V), as they are called by the local producers, classified empirically according to their morphological characteristics. All selected trees (males and females) were 30-35 years old. Mature composite leaves from the 20 selected plants were collected in July from Chios and kept in the herbarium of the Laboratory of Floriculture in Thermi (Thessaloniki, Greece), with code numbers PL1901-PL1920.

Table 1. Plant collection areas in Southern Chios Island, coding and coordinates of ten female (F) and ten male (M) selected genotypes of P. lentiscus var. Chia.

\begin{tabular}{|c|c|c|c|c|c|}
\hline Code & Area & Gender & Cultivar & Coordinates $\mathrm{X}$ & Coordinates $Y$ \\
\hline $2 \mathrm{~F}$ & Sikilia & Female & - & $680268 \mathrm{E}$ & $4237306 \mathrm{~N}$ \\
\hline $3 F$ & Kadi Petra & Female & - & $680051 \mathrm{E}$ & $4236549 \mathrm{~N}$ \\
\hline $6 \mathrm{~F}$ & Fragma & Female & - & $679009 \mathrm{E}$ & $4234120 \mathrm{~N}$ \\
\hline $7 \mathrm{~F}$ & Fragma & Female & - & $679005 \mathrm{E}$ & $4234099 \mathrm{~N}$ \\
\hline $8 \mathrm{~F}$ & Fragma & Female & - & $678999 \mathrm{E}$ & $4234138 \mathrm{~N}$ \\
\hline $10 \mathrm{~F}$ & Kini & Female & - & $679736 \mathrm{E}$ & $4235717 \mathrm{~N}$ \\
\hline $12 \mathrm{~F}$ & Lilika & Female & - & $680375 \mathrm{E}$ & $4231255 \mathrm{~N}$ \\
\hline $14 \mathrm{~F}$ & $\begin{array}{c}\text { Agios } \\
\text { Nikolaos }\end{array}$ & Female & - & $681586 \mathrm{E}$ & $4232578 \mathrm{~N}$ \\
\hline $16 \mathrm{~F}$ & Kataraktis & Female & - & $683195 \mathrm{E}$ & $4237363 \mathrm{~N}$ \\
\hline $19 \mathrm{~F}$ & Pyrgi & Female & - & $675817 \mathrm{E}$ & $4232291 \mathrm{~N}$ \\
\hline $1 \mathrm{M}$ & Metochi & Male & 'Mavroschinos' & $677700 \mathrm{E}$ & $4230294 \mathrm{~N}$ \\
\hline $6 \mathrm{M}$ & Rouchouni & Male & 'Mavroschinos' & $682558 \mathrm{E}$ & $4236737 \mathrm{~N}$ \\
\hline $7 \mathrm{M}$ & AgiosGiannis & Male & 'Votomos' & $679714 \mathrm{E}$ & $4235678 \mathrm{~N}$ \\
\hline $8 \mathrm{M}$ & Loupadiotis & Male & 'Psilophyllos' & $680325 \mathrm{E}$ & $4234579 \mathrm{~N}$ \\
\hline $10 \mathrm{M}$ & Schinari & Male & 'Maroulitis' & $684075 \mathrm{E}$ & $4240009 \mathrm{~N}$ \\
\hline $15 \mathrm{M}$ & Kroulos & Male & 'Platiphyllos' & $675399 \mathrm{E}$ & $4231913 \mathrm{~N}$ \\
\hline $18 \mathrm{M}$ & Grapti & Male & 'Psilophyllos' & $680694 \mathrm{E}$ & $4237690 \mathrm{~N}$ \\
\hline $21 \mathrm{M}$ & Agios Minas & Male & 'Maroulitis' & $684897 \mathrm{E}$ & $4241130 \mathrm{~N}$ \\
\hline $36 \mathrm{M}$ & DitiaMonastiri & Male & 'Platiphyllos' & $676043 \mathrm{E}$ & $4226922 \mathrm{~N}$ \\
\hline $61 \mathrm{M}$ & P. Monolia & Male & 'Votomos' & $681112 \mathrm{E}$ & $4235848 \mathrm{~N}$ \\
\hline
\end{tabular}

\subsection{Rooting of Shoot Cuttings}

Apical shoots of the selected P. lentiscus var. Chia trees, $15 \mathrm{~cm}$ in length, were cut during winter and kept at $4^{\circ} \mathrm{C}$ for one day. The selected season was chosen as the most suitable for rooting of $P$. lentiscus shoot cuttings, according to previous research of Kostas et al. [18]. Afterward, the cut of the basal part of the shoot cutting was renewed, leading to a final length of $12 \mathrm{~cm}$, while the leaves of the base of the shoot cuttings were removed. Thus, each cutting had 2-3 composite leaves on the top. Furthermore, the basal portion of the shoot cutting, about 1.5-2 cm in length, was dipped into different concentrations $\left(0,4,8\right.$ or $\left.16 \mathrm{~g} \cdot \mathrm{L}^{-1}\right)$ of K-IBA (Sigma-Aldrich, St. Louis, MO, USA) for $10 \mathrm{~s}$ and planted in $9 \mathrm{~L}$ volume plastic boxes (with holes at their base for drainage) filled with perlite (Isocon, Agios Ioannis, Greece) (Figure 1A). Afterward, the shoot cuttings were transferred for rooting in a fog system, with the relative humidity (RH) adjusted to 93-95\% (Figure 1B). Forty shoot cuttings were used for each K-IBA treatment. At the end of a 4-month period, rooting $(\%)$, as well as number and length $(\mathrm{cm})$ of roots, were evaluated (Figure $1 \mathrm{C})$. 


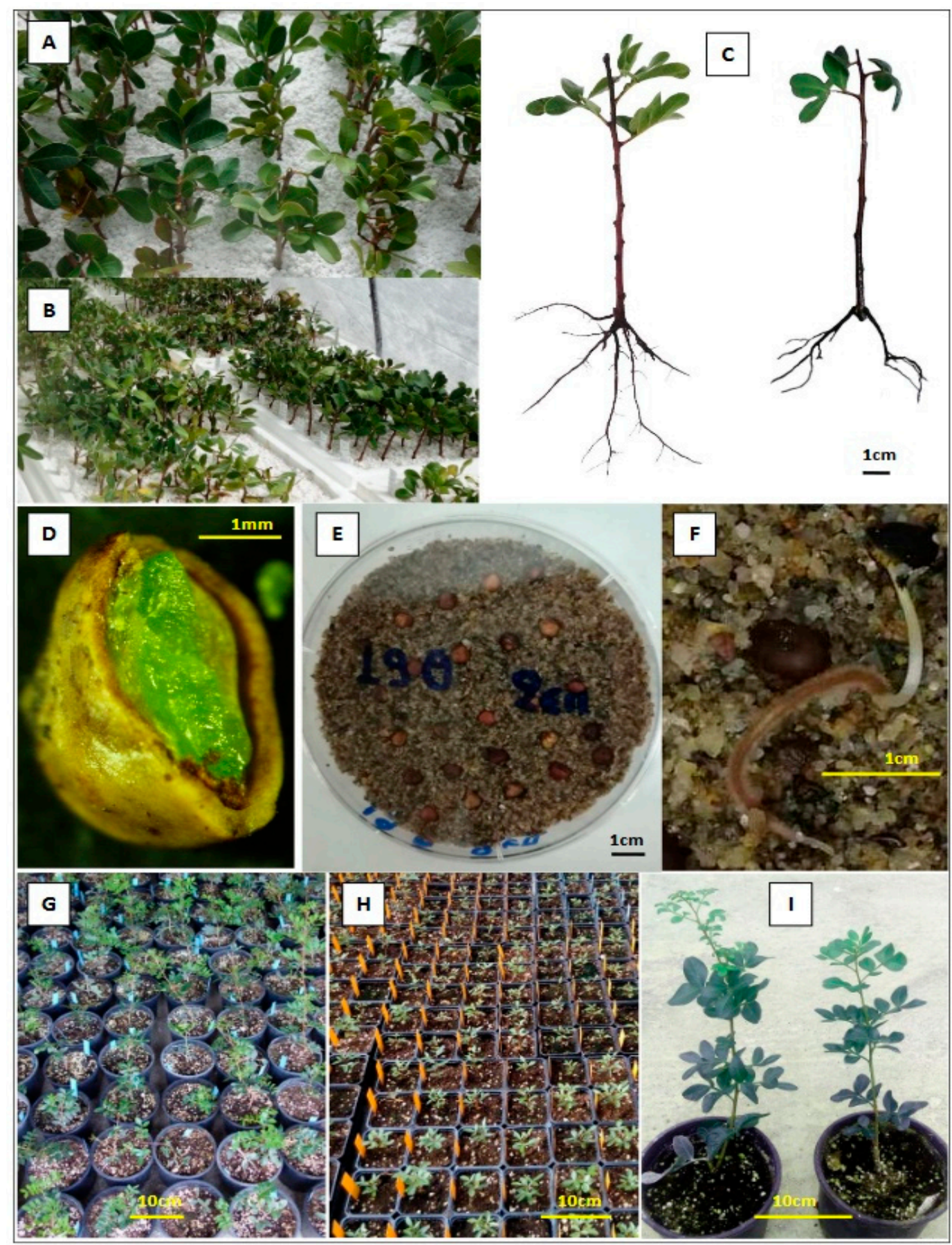

Figure 1. Shoot cuttings of $P$. lentiscus var. Chia planted for rooting in perlite (A), shoot cuttings in $9 \mathrm{~L}$ volume plastic boxes in the fog system $(\mathbf{B})$, rooted shoot cuttings with the application of $4 \mathrm{~g} \cdot \mathrm{L}^{-1} \mathrm{~K}$-IBA (on the left) and without K-IBA (on the right), respectively (C), seed incision of P. lentiscus var. Chia with a healthy embryo (green) (D), Petri dish $9 \mathrm{~cm}$ containing sterilized sand and 25 seeds of genotype 19F (E), germinated seed (genotype 2F) of P. lentiscus var. Chia, two weeks after seed sowing (F), plantlets derived from rooted shoot cuttings, two months after transplanting into $1.5 \mathrm{~L}$ pots (G), young seedlings, three months after seed germination $(\mathbf{H})$, P. lentiscus var. Chia plantlets produced from rooted shoot cuttings six months after transplantation (I).

The experiment was conducted in a completely randomized design, with forty replicates per treatment in each genotype. The rooting percentages were subjected to arcsine transformation prior to statistical analysis and were transformed back to percentages for presentation in tables [24]. The transformed data were checked for normality and ho- 
mogeneity and then analyzed based on analysis of variance (ANOVA). The means were compared using Duncan's multiple range test [25]. The statistical analysis was carried out using the statistical package SPSS 25 (IBM, Armonk, NY, USA).

\subsection{Germination of Seeds}

Ripe fruits from each of the ten selected female genotypes of P. lentiscus var. Chia were harvested in three different time-periods (15 October, 30 November and 15 January). All the fruit samples were immediately transported to Thessaloniki from the Island of Chios and stored at the Laboratory of Floriculture, School of Agriculture, Aristotle University. Afterward, the fruits (one-seeded drupe consisted of exocarp, mesocarp and a stony endocarp enclosing the seed) of each genotype were pulped separately manually, and the exocarp and mesocarp were removed using sieves and running tap water. Then, the clean seeds (endocarp plus true seed) were immersed in tap water, and any floating seeds were removed and counted. It was ascertained that these seeds were inappropriate for germination since they had malformed embryos. The viable submerged seeds were counted (Figure 1D), spread out on filter papers and left to dry for 3 days under laboratory conditions. After drying, they were used for the germination experiments. In the present study, the term "seed" refers to the true seed plus the endocarp.

To determine the effect of the scarification using sulphuric acid $\left(\mathrm{H}_{2} \mathrm{SO}_{4}\right)$ on germination of seeds of each genotype, seeds collected in the middle of the collection period (30 November) were immersed in a beaker containing concentrated $(96 \%)\left(\mathrm{H}_{2} \mathrm{SO}_{4}\right)$ (three volumes of $\mathrm{H}_{2} \mathrm{SO}_{4}$ per volume of seeds) for 0 (control), 2.5, 5 or 10 min under gentle stirring. From preliminary experiments (data not shown), it was observed that immersing time in $\mathrm{H}_{2} \mathrm{SO}_{4}$ longer than 10 min destroyed the seeds. Afterward, the seeds were gently removed from the $\mathrm{H}_{2} \mathrm{SO}_{4}$ and washed initially five times with tap water and finally once with distilled water under continuous stirring. In another experiment, in order to determine the effect of the fruit harvesting period on germination, seeds from each selected genotype from the three collections (15 October, 30 November and 15 January) were immersed in concentrated $(96 \%) \mathrm{H}_{2} \mathrm{SO}_{4}$ for $2.5 \mathrm{~min}$ following the same procedure as previously described.

Furthermore, the seeds of both experiments were placed on sterilized river sand moistened with distilled water in $9 \mathrm{~cm}$ plastic Petri dishes and were transferred to growth chambers, with the temperature adjusted to $23 \pm 0.1{ }^{\circ} \mathrm{C}$ and the photoperiod to $12 \mathrm{~h}$ (Figure 1E). The Petri dishes were randomly arranged on the growth chamber shelves, and the sand was rewetted with distilled water when needed. Germinated seeds were recorded every week for a 4-week period (Figure 1F).

In both experiments, a completely randomized design was applied. For each treatment, there were four replications of 25 seeds each. Seeds were considered to have been germinated when at least a $2 \mathrm{~mm}$ long radicle has emerged [26]. Finally, for each treatment, the germination percentage was calculated as the average of the four replications. The germination percentages data were firstly arcsine-square-root-transformed, checked for normality and homogeneity of variances [24] and then were analyzed by one-way ANOVA. The means were compared using Duncan's multiple range test [25], and the statistical analysis was carried out using the statistical package SPSS 25 (IBM, Armonk, NY, USA).

\subsection{Morphological Traits Recording}

The twenty selected plants were morphologically recorded, based on the description/analysis of morphological traits of the relative species of Pistacia vera conducted by Barone et al. [27], with some modifications. The selection and recording of the morphological traits of the genotypes of P. lentiscus var. Chia was focused on the properties that were mainly related to their ornamental value. The 13 traits that were recorded were: growth habit, leaf length, leaf width, number of leaflets, terminal leaflets length, terminal leaflets width, terminal leaflets shape, terminal leaflets apex, terminal leaflets base, plant height, plant diameter and in the female genotypes fruit yielding and seed size as well. The 
recorded morphological traits and the variations of each of them are shown in Table 2 and in more detail in the Supplementary Table S1. For traits No. 1 and 10-12, the recorded values were based on personal experience and observation and determined by an experienced agronomist, a member of the scientific/research team of the Chios Mastic Gum Growers Association. For traits No. 2-9 (leaves and leaflets measurements), 20 composite leaves were collected at the adult stage from each genotype, coming from the middle height of the plant canopy. The leaves were collected at the end of July, and the various traits were measured using a digital caliper with a sensitivity of $\pm 0.1 \mathrm{~mm}$ or in cases that were based on comparisons with leaflets patterns, as described in the Supplementary Table S1 [27]. All the measurements of a trait were made on the same date to avoid differences from the environmental conditions and/or developmental stages of the plant. The statistical analysis of the data was based on ANOVA with the use of the statistical package SPSS 25 (IBM, Armonk, NY, USA), while the separation of the means was made with Duncan's multiple range test. The Pearson's correlation test was performed to determine the relationships among the morphological traits.

Table 2. Morphological traits presentation for the 20 selected genotypes of P. lentiscus var. Chia focusing on properties related mainly to the appearance of the trees and their ornamental value.

\begin{tabular}{|c|c|c|c|c|c|}
\hline \multirow[b]{2}{*}{ Morphological Traits } & \multicolumn{5}{|c|}{ Description } \\
\hline & 1 & 2 & 3 & 4 & 5 \\
\hline 1. Growth habit & Erect & Semi-erect & Spreading & Drooping & \\
\hline 2. Leaf length & \multicolumn{5}{|c|}{ In $\mathrm{cm}$, measured from the base of petiole to the tip of terminal leaflets } \\
\hline 3. Leaf width & \multicolumn{5}{|c|}{ In $\mathrm{cm}$, measured at the widest part } \\
\hline 4. Number of leaflets & \multicolumn{5}{|c|}{ Number of leaflets of composite leaf } \\
\hline 5. Terminal leaflets length & \multicolumn{5}{|c|}{ In $\mathrm{cm}$, measured from the base to the tip of terminal leaflets } \\
\hline 6. Terminal leaflets width & \multicolumn{5}{|c|}{ In $\mathrm{cm}$, measured at the widest part of terminal leaflets } \\
\hline 7. Terminal leaflets shape & Broad lanceolate & Elliptic & Ovate & Round ovate & Roundish \\
\hline 8. Terminal leaflets apex & Acuminate & Mucronate & Mucronulate & Obtuse & Retuse \\
\hline 9. Terminal leaflets base & Attenuate & Obtuse & Truncate & Oblique & \\
\hline 10. Plant height & Small & Medium & Big & & \\
\hline 11. Plant diameter & Small & Medium & Big & & \\
\hline 12. Fruit yielding, in females & Low & Medium & High & & \\
\hline 13. Seed size, in females & \multicolumn{5}{|c|}{ In $\mathrm{mm}$, measured at the longest part } \\
\hline
\end{tabular}

\subsection{Genomic DNA Extraction and PCR Amplification Conditions}

Genomic DNA was extracted from the leaves of the 20 selected P. lentiscus var. Chia plants with NucleoSpin Plant II kit (Macherey-Nagel, Düren, Germany). The genomic DNA's quantity and quality were determined using a Q3000 UV Spectrophotometer (Quawell Technology Inc., San Jose, CA, USA). DNA samples were stored at $-20{ }^{\circ} \mathrm{C}$, until further use.

Twenty-one ISSR primers were initially tested, and based on preliminary results, eight of them (UBC 827, 807, 818, 811, 856, 808, 834, 841) [28-30] which gave reproducible results, were selected for further use (Table S2). The ISSR amplification reactions were performed each in a final volume of $10 \mu \mathrm{L}$ containing $50 \mathrm{ng}$ total DNA with the use of KAPA2G fast PCR kit (Kapa Biosystems, Cape Town, South Africa) following the supplier's instructions.

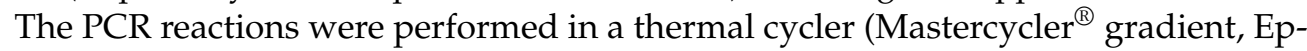
pendorf AG, Hamburg, Germany) using the following amplification profile: an initial denaturation step at $95^{\circ} \mathrm{C}$ for 3 min was followed by 30 cycles of $15 \mathrm{~s}$ denaturation at $95^{\circ} \mathrm{C}$ for $15 \mathrm{~s}$, annealing at $60^{\circ} \mathrm{C}$ for $15 \mathrm{~s}$ and extension at $72{ }^{\circ} \mathrm{C}$ for $45 \mathrm{~s}$. This was followed by 
a final extension step at $72{ }^{\circ} \mathrm{C}$ for $3 \mathrm{~min}$. DNA amplification fragments were separated in a $1.5 \%$ agarose gel with $1 \mathrm{X}$ TAE buffer, stained with ethidium bromide $\left(0.5 \mu \mathrm{g} \cdot \mathrm{mL}^{-1}\right)$ and analyzed using the Kodak 1D analysis software (Eastman Kodak Company, Rochester, NY, USA). The size of the amplification products was calculated based on molecular mass $1 \mathrm{~Kb}$ DNA ladder plus DNA ladder (Nippon Genetics Europe, Dueren, Germany). Two independent PCR amplification reactions were performed for each sample.

For the ISSR profiles, the fragments ranging from 150 to $3000 \mathrm{bp}$ were scored as present or absent. Scoring was based on the formula: the number of genotypes analyzed $\mathrm{X}$ number of band classes produced with all eight ISSR primers. After calculation of the average number of polymorphic bands per primer, the data were used to detect the relationship among the 20 genotypes. These data were converted by cluster analysis based on the Nei genetic distance [31] and used for the construction of the principal coordinate analysis (PCoA) with the implementation of GenAlEx 6.501 program, or data were analyzed using MEGA 4 v.4.1 software [32] for the construction of an unweighted paired group method of cluster analysis (UPGMA). For the detection of any genetic changes, all ISSR results were compared to each other for all DNA samples. The data for each molecular marker was entered into a computer file as a binary table, and then tables were analyzed by genetic analysis in Excel with the cross-platform package GenAlEx 6 [33]. The similarity of the qualitative data was calculated using the similarity index of Nei and Li [34], and the results were presented by the principal coordinates analysis (PCoA). The similarity coefficients calculated by GenAlEx 6 were converted to MEGA 4 v.4.1 software [32], and the resulting complexes were expressed in the form of a dendrogram, where similarity estimates were analyzed using the unweighted pair group method with arithmetic means (UPGMA). The polymorphism information content $(P I C)$ for each primer locus was calculated from the number of bands per primer using the formula $P I C=1-\Sigma(P i)^{2}$, where $P i$ is the frequency of the $i$ th band in the genotype examined [35]

\subsection{Correlation of Morphological Traits with ISSR Markers}

The estimation of the association between the ISSR indices and the quantitative morphological characteristics was calculated through the stepwise multiple regression analysis (MRA) using the stepwise linear regression of statistical package SPSS 25 (IBM, Armonk, NY, USA). With this method, each ISSR marker was treated as an independent variable, while each quantitative or qualitative characteristic was treated as a dependent variable. The analysis was based on a model that correlates the dependence of the dependent variable with a linear function of the set of independent variables, representing ISSR markers [36]. Values of the F with 0.045 and 0.099 probabilities were used to enter and remove, respectively, the selected independent variables for the regression equation [37]. The $R^{2}$ denotes the square of $r$, the multiple correlation coefficient and the beta value are defined as the standardized regression coefficient [38,39].

\section{Results and Discussion}

\subsection{Asexual Propagation}

The application of K-IBA greatly influenced the rooting of the shoot cuttings of the selected genotypes with the concentration of $4 \mathrm{~g} \cdot \mathrm{L}^{-1}$ found to be significantly the best, especially for the genotypes 3F, 7M, 8M and 21M (rooting 27.5, 55.0, 62.5 and 45.0\%, respectively) (Figures $1 \mathrm{C}$ and 2). Similarly, the concentrations of 8 and $16 \mathrm{~g} \cdot \mathrm{L}^{-1}$ of K-IBA significantly increased the percentages of rooting in most genotypes, with the exception of the genotypes $3 \mathrm{~F}, 8 \mathrm{~F}, 12 \mathrm{~F}, 19 \mathrm{~F}, 7 \mathrm{M}, 15 \mathrm{M}, 21 \mathrm{M}$ and $3 \mathrm{~F}, 8 \mathrm{~F}, 10 \mathrm{~F}, 1 \mathrm{M}, 7 \mathrm{M}, 8 \mathrm{M}, 21 \mathrm{M}, 36 \mathrm{M}, 61 \mathrm{M}$, respectively (Figure 2). There were no differences between the concentrations of 4 and $8 \mathrm{~g} \cdot \mathrm{L}^{-1}$ of K-IBA on rooting of the genotypes $2 \mathrm{~F}, 6 \mathrm{~F}, 7 \mathrm{~F}, 10 \mathrm{~F}, 14 \mathrm{~F}, 16 \mathrm{~F}, 1 \mathrm{M}, 6 \mathrm{M}, 10 \mathrm{M}, 18 \mathrm{M}$, $36 \mathrm{M}$ and $61 \mathrm{M}$, as well as between 4 and $16 \mathrm{~g} \cdot \mathrm{L}^{-1}$ of $\mathrm{K}-\mathrm{IBA}$ on rooting of the genotypes $2 \mathrm{~F}, 6 \mathrm{~F}, 12 \mathrm{~F} 16 \mathrm{~F}, 19 \mathrm{~F}, 6 \mathrm{M}, 10 \mathrm{M}, 15 \mathrm{M}$ and $18 \mathrm{M}$. On the other hand, in treatments without application of K-IBA, the shoot cuttings rooted poorly (rooting 7.5-15.0\%) (Figures 1C and 2) or not at all (e.g., in genotypes 3F, 6F, 7F, 8F, 10F, 12F, 14F, 16F, 10M, 18M, 21M and 61M). 
It is known that the plant growth regulators of the auxin type, such as K-IBA, indolebutyric acid (IBA) and a-naphthalene acetic acid (NAA), favor the rooting of shoot cuttings in the majority of plant species. Although rooting of P. lentiscus shoot cuttings is considered to be very difficult $[17,40]$, there are reports on successful rooting of shoot cuttings of this species with the aid of various plant growth regulators and concentrations [18,41]. Isfendiyaroglu [41] used IBA (dissolved in 50\% isopropanol) with the best results at the concentration of $20 \mathrm{~g} \cdot \mathrm{L}^{-1}$, in contrast to our best concentration of $4 \mathrm{~g} \cdot \mathrm{L}^{-1} \mathrm{~K}$-IBA (dissolved in water). This discrepancy could be attributed to the different genotypes and physiological status of the shoot cuttings used, as well as to the different experimental conditions applied.

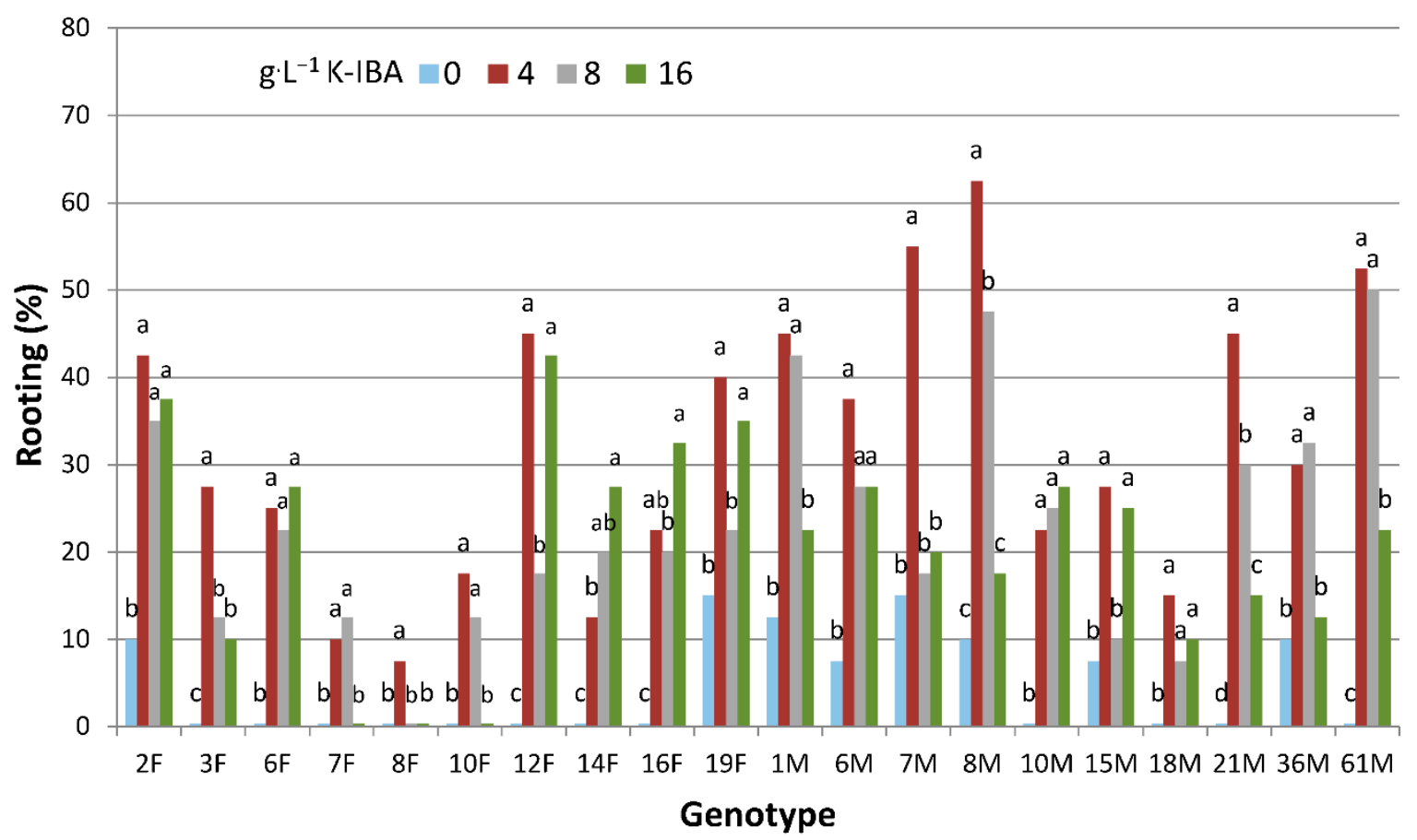

Figure 2. Effect of different concentrations of K-IBA on rooting (\%) of shoot cuttings of ten male and ten female genotypes of $P$. lentiscus var. Chia in winter. Different letters in each genotype indicate statistically significant differences among the concentrations of K-IBA tested according to Duncan's multiple range test at $p \leq 0.05$.

It seems that the genotype is an important factor for the rooting of P. lentiscus var. Chia shoot cuttings. Without the application of K-IBA, the rooting percentage was low, while a number of genotypes did not root at all (Table S3). With the application of $4 \mathrm{~g} \cdot \mathrm{L}^{-1} \mathrm{~K}$-IBA the highest rooting rates were observed in the genotypes $7 \mathrm{M}(62.5 \%)$ and $8 \mathrm{M}(55.0 \%)$ (Table S3), which both belong to cultivar 'Psilophyllos', followed, without a statistical difference, by the genotype $61 \mathrm{M}(52.5 \%$, cultivar 'Votomos'). The lowest rooting rate $(15.0 \%)$ was found in genotype $18 \mathrm{M}$, which belongs to cultivar 'Votomos'. In treatments with $8 \mathrm{~g} \cdot \mathrm{L}^{-1}$ of K-IBA, the highest percentages $(50.0 \%, 47.5 \%$ and $42.5 \%)$ were noticed in genotypes $61 \mathrm{M}$ ('Votomos'), 8M ('Psilophyllos') and 1M ('Mavroschinos'), respectively, whereas the lowest percentages $(10.0 \%$ and $7.5 \%)$ were noticed in genotypes $15 \mathrm{M}$ ('Platiphyllos') and $18 \mathrm{M}$ ('Maroulitis'). The application of K-IBA at a concentration of $16 \mathrm{~g} \cdot \mathrm{L}^{-1}$ gave rooting rates under $30 \%$ in all genotypes. The highest percentages were observed in genotypes $6 \mathrm{M}, 10 \mathrm{M}$ and $15 \mathrm{M}$ and the lowest in the $18 \mathrm{M}$ and $36 \mathrm{M}$ (Table S3). The results showed that the genotype gender did not influence the rooting ability of the shoot cuttings. Thus, in both male and female plants, the genotype was the crucial factor, while a large variation in rooting rates $(7.5-62.5 \%)$ was noticed between them (Table S3). The significant role of the genotype on the rooting of P. lentiscus shoot cuttings was also mentioned by Kostas et al. [18] and Isfendiyaroglu [41]. Figure 1G,I show plantlets grew from rooted shoot cuttings of P. lentiscus var. Chia. 
The application of K-IBA positively influenced the number and length of new roots formed as compared with the control (zero K-IBA) in all genotypes (Table 3). In most cases, the application of K-IBA over doubled the number of roots formed (average 4.6 roots/cutting) in comparison with the control (average 2.2 roots/cutting) (Table 3, Figure 1C). However, there were no statistical differences concerning the number of roots formed among the genotypes in the three concentrations of K-IBA applied (Table 3). The same trend was also noticed for the effect of the K-IBA on the length of the roots formed on the shoot cuttings, which, however, was two-fold (average $5.8 \mathrm{~cm}$ ) over the length of the control (average $2.9 \mathrm{~cm}$ ) (Table 3). Differentiations concerning the length of roots were observed among genotypes. Thus, the genotypes $8 \mathrm{M}, 21 \mathrm{M}$ and $61 \mathrm{M}$ had longer roots than the genotype $15 \mathrm{M}$ at $4 \mathrm{~g} \cdot \mathrm{L}^{-1} \mathrm{~K}-\mathrm{IBA}$, while the genotypes $7 \mathrm{M}$ and $15 \mathrm{M}$ had longer roots as compared with the genotype $18 \mathrm{M}$ at $16 \mathrm{~g} \cdot \mathrm{L}^{-1} \mathrm{~K}$-IBA. The number and length of roots could be one of the criteria for evaluating the rooting system of a shoot cutting in the genotypes of P. lentiscus var. Chia (Figure 3). Kostas et al. [18] also reported the formation of a greater number and length of roots in P. lentiscus var. Chia shoot cuttings with the application of K-IBA in comparison with the control. Similarly, Isfendiyaroglu [41], working with other genotypes of $P$. lentiscus, reported also more and longer roots formed on the shoot cuttings by using IBA with a large variation among the genotypes tested.

Table 3. Effect of different concentrations of K-IBA on the root number and length $(\mathrm{cm})$ of the 20 genotypes of $P$. lentiscus var. Chia shoot cuttings rooted in winter.

\begin{tabular}{|c|c|c|c|c|c|c|c|c|}
\hline \multirow[b]{3}{*}{ Genotype } & \multicolumn{4}{|c|}{ Number of Roots } & \multicolumn{4}{|c|}{ Length of Roots (cm) } \\
\hline & \multicolumn{4}{|c|}{ K-IBA Concentration $\left(g \cdot \mathrm{L}^{-1}\right)$} & \multicolumn{4}{|c|}{ K-IBA Concentration $\left(\mathrm{g} \cdot \mathrm{L}^{-1}\right)$} \\
\hline & 0 (Control) & 4 & 8 & 16 & 0 (Control) & 4 & 8 & 16 \\
\hline $1 \mathrm{M}$ & $1.80 b^{*}$ & $4.72 \mathrm{a}$ & $4.41 \mathrm{a}$ & $4.89 \mathrm{a}$ & $3.20 b^{*}$ & $6.11 \mathrm{a}$ & $5.88 a$ & $5.78 \mathrm{a}$ \\
\hline $6 \mathrm{M}$ & $1.67 \mathrm{~b}$ & $4.60 \mathrm{a}$ & $3.91 \mathrm{a}$ & $4.36 \mathrm{a}$ & $2.33 b$ & $6.00 \mathrm{a}$ & $4.55 \mathrm{a}$ & $5.36 a$ \\
\hline $7 \mathrm{M}$ & $2.00 \mathrm{~b}$ & $5.23 a$ & $4.71 \mathrm{a}$ & $4.38 \mathrm{a}$ & $2.50 \mathrm{~b}$ & $5.91 \mathrm{a}$ & $6.00 \mathrm{a}$ & $6.38 \mathrm{a}$ \\
\hline $8 \mathrm{M}$ & $2.00 \mathrm{~b}$ & $4.64 \mathrm{a}$ & $4.95 \mathrm{a}$ & $5.00 \mathrm{a}$ & $2.00 \mathrm{~b}$ & $6.28 \mathrm{a}$ & $6.32 \mathrm{a}$ & $6.14 \mathrm{a}$ \\
\hline $10 \mathrm{M}$ & - & $4.88 \mathrm{a}$ & $4.10 \mathrm{a}$ & $4.55 \mathrm{a}$ & - & $4.75 \mathrm{a}$ & $5.70 \mathrm{a}$ & $5.64 \mathrm{a}$ \\
\hline $15 \mathrm{M}$ & $1.67 \mathrm{~b}$ & $3.73 a$ & $4.50 \mathrm{a}$ & $4.80 \mathrm{a}$ & $2.67 c$ & $4.09 \mathrm{~b}$ & $4.50 \mathrm{ab}$ & $6.20 \mathrm{a}$ \\
\hline $18 \mathrm{M}$ & - & $4.83 a$ & $3.33 a$ & $4.50 \mathrm{a}$ & - & $4.83 a$ & $5.67 \mathrm{a}$ & $4.25 \mathrm{a}$ \\
\hline $21 \mathrm{M}$ & - & $4.72 \mathrm{a}$ & $4.50 \mathrm{a}$ & $5.17 \mathrm{a}$ & - & $6.28 \mathrm{a}$ & $6.33 a$ & $5.33 a$ \\
\hline $36 \mathrm{M}$ & $1.75 b$ & $4.25 \mathrm{a}$ & $5.15 a$ & $4.40 \mathrm{a}$ & $2.25 b$ & $6.00 \mathrm{a}$ & $6.08 \mathrm{a}$ & $5.20 \mathrm{a}$ \\
\hline $61 \mathrm{M}$ & - & $4.62 \mathrm{a}$ & $4.85 a$ & $4.22 \mathrm{a}$ & - & $6.33 a$ & $6.25 a$ & $6.00 \mathrm{a}$ \\
\hline $2 \mathrm{~F}$ & $2.00 \mathrm{~b}$ & $5.00 \mathrm{a}$ & $4.43 a$ & $4.20 \mathrm{a}$ & $3.00 \mathrm{~b}$ & $5.65 a$ & $6.29 a$ & $6.00 \mathrm{a}$ \\
\hline $3 F$ & - & $4.36 a$ & $4.20 \mathrm{a}$ & $4.75 a$ & - & $5.91 \mathrm{a}$ & $5.80 \mathrm{a}$ & $6.25 a$ \\
\hline $6 \mathrm{~F}$ & - & $4.56 a$ & $4.91 \mathrm{a}$ & $4.91 \mathrm{a}$ & - & $6.44 a$ & $6.09 a$ & $5.45 \mathrm{a}$ \\
\hline $7 \mathrm{~F}$ & - & $4.25 \mathrm{a}$ & $5.60 \mathrm{a}$ & - & - & $5.75 a$ & $5.80 \mathrm{a}$ & - \\
\hline $8 \mathrm{~F}$ & - & $5.00 \mathrm{a}$ & - & - & - & $6.00 \mathrm{a}$ & - & - \\
\hline $10 \mathrm{~F}$ & - & $4.29 a$ & $4.60 \mathrm{a}$ & - & - & $5.43 a$ & $6.00 \mathrm{a}$ & - \\
\hline $12 \mathrm{~F}$ & - & $3.78 \mathrm{a}$ & $4.86 a$ & $4.82 \mathrm{a}$ & - & $5.71 \mathrm{a}$ & $5.57 \mathrm{a}$ & $5.88 \mathrm{a}$ \\
\hline $14 \mathrm{~F}$ & - & $4.60 \mathrm{a}$ & $4.50 \mathrm{a}$ & $5.09 \mathrm{a}$ & - & $5.40 \mathrm{a}$ & $5.88 \mathrm{a}$ & $6.35 \mathrm{a}$ \\
\hline $16 \mathrm{~F}$ & - & $4.67 \mathrm{a}$ & $4.00 \mathrm{a}$ & $5.00 \mathrm{a}$ & - & $6.22 a$ & $6.13 a$ & $6.38 \mathrm{a}$ \\
\hline $19 \mathrm{~F}$ & $1.83 b$ & $4.75 a$ & $4.67 \mathrm{a}$ & $4.36 a$ & $3.50 \mathrm{~b}$ & $5.88 \mathrm{a}$ & $6.22 \mathrm{a}$ & $6.21 \mathrm{a}$ \\
\hline Average & $2.19 b$ & $4.57 \mathrm{a}$ & $4.54 a$ & $4.67 \mathrm{a}$ & $2.94 b$ & $5.75 a$ & $5.84 a$ & $5.85 \mathrm{a}$ \\
\hline
\end{tabular}

* Different letters in each line of the number of roots and in each line of the length of roots indicate statistically significant differences according to Duncan's multiple range test at $p \leq 0.05$. The symbol "-"means no rooting. 


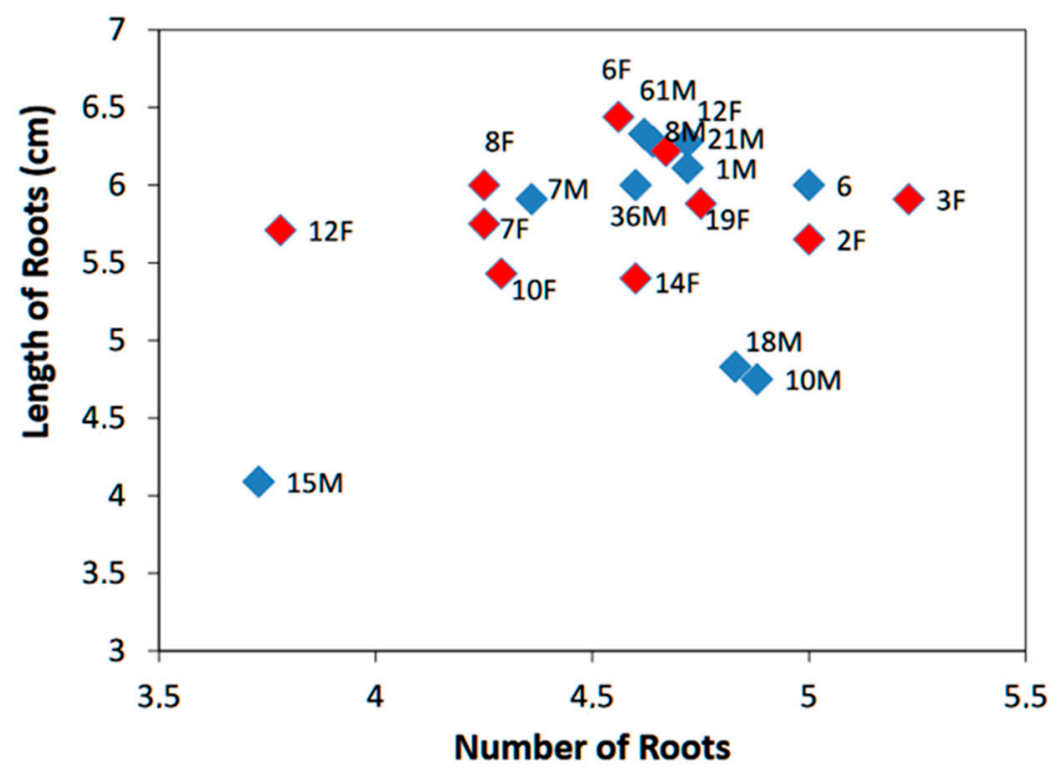

Figure 3. Cluster analysis of the number of roots (vertical) and length of roots (horizontal) of female (red) and male (blue) genotypes of $P$. lentiscus var. Chia shoot cuttings rooted in winter, with the application of $4 \mathrm{~g} \cdot \mathrm{L}^{-1} \mathrm{~K}-\mathrm{IBA}$. The genotypes on the upper part and to the right are the most successful in rooting, as they form more and longer roots.

\subsection{Sexual Propagation}

The effect of the collection time and scarification with $\mathrm{H}_{2} \mathrm{SO}_{4}$ on seed germination varied among P. lentiscus var. Chia genotypes. In the first experiment, the scarification of seeds with $\mathrm{H}_{2} \mathrm{SO}_{4}$ had a significant effect on germination (\%) of the genotypes $7 \mathrm{~F}$ and $12 \mathrm{~F}$ only, whereas, in the rest eight genotypes, the seed germination was not positively affected by the scarification (Figure 4). In the genotypes, 2F, 6F, 10F, 16F and 19F (germination $10-55 \%$ ), no significant differences were observed in germination percentages between control and seeds scarified for $2.5 \mathrm{~min}$. These results demonstrated that in these genotypes, the endocarp plus seed coat did not inhibit the imbibition and consequently the germination process. Moreover, in the first week, the treatment with $\mathrm{H}_{2} \mathrm{SO}_{4}$ increased the number of germinated seeds in comparison with the control (Table S4). It is possible that the scarified seeds imbibed water faster, and therefore the germination process was accelerated. The same evidence was also provided by Piotto [12], who found that the scarification treatment on P. lentiscus seeds significantly increased the speed of the germination process, but the final germination percentage was not affected. Furthermore, Garcia-Fayos and Verdu [14] and Isfendiyaroglu [15] stated that it is not needed any treatment for the germination of P. lentiscus seeds as they do not show dormancy. In contrast, Abu-Qaoud [13] claimed that 15-min scarification with $\mathrm{H}_{2} \mathrm{SO}_{4}$ followed by either a 1-month period of cold stratification or treatment with 1000 ppm GA 3 significantly improved the germination percentages of P. lentiscus seeds. However, in the present study, scarification with $\mathrm{H}_{2} \mathrm{SO}_{4}$ for 2.5 min or for 2.5 and $5 \mathrm{~min}$ resulted in higher germination percentages than without scarification only in genotypes 7F and 12F, respectively. Fruits of some species of the Anacardiaceae family have physical dormancy because the endocarp is impermeable to water [42]. Furthermore, Pipinis et al. [43,44], studying the germination of Cotinus coggygria and Rhus corriaria seeds (both species belong to the Anacardiaceae family), reported that the scarification with $\mathrm{H}_{2} \mathrm{SO}_{4}$ was necessary to break the physical dormancy of seeds of both species. In the present study, only in the genotypes $7 \mathrm{~F}$ and $12 \mathrm{~F}$, out of the ten studied ones, the endocarp seemed to be impermeable to water and to inhibit the germination process. According to Baskin and Baskin [42], the seed coat has the same genetic composition as the maternal parent. Thus, the genotype of the maternal parent has a significant effect on germination, and therefore the knowledge of the genetics of the maternal parent is very useful in predicting the germination behavior of P. lentiscus var. Chia seeds. 


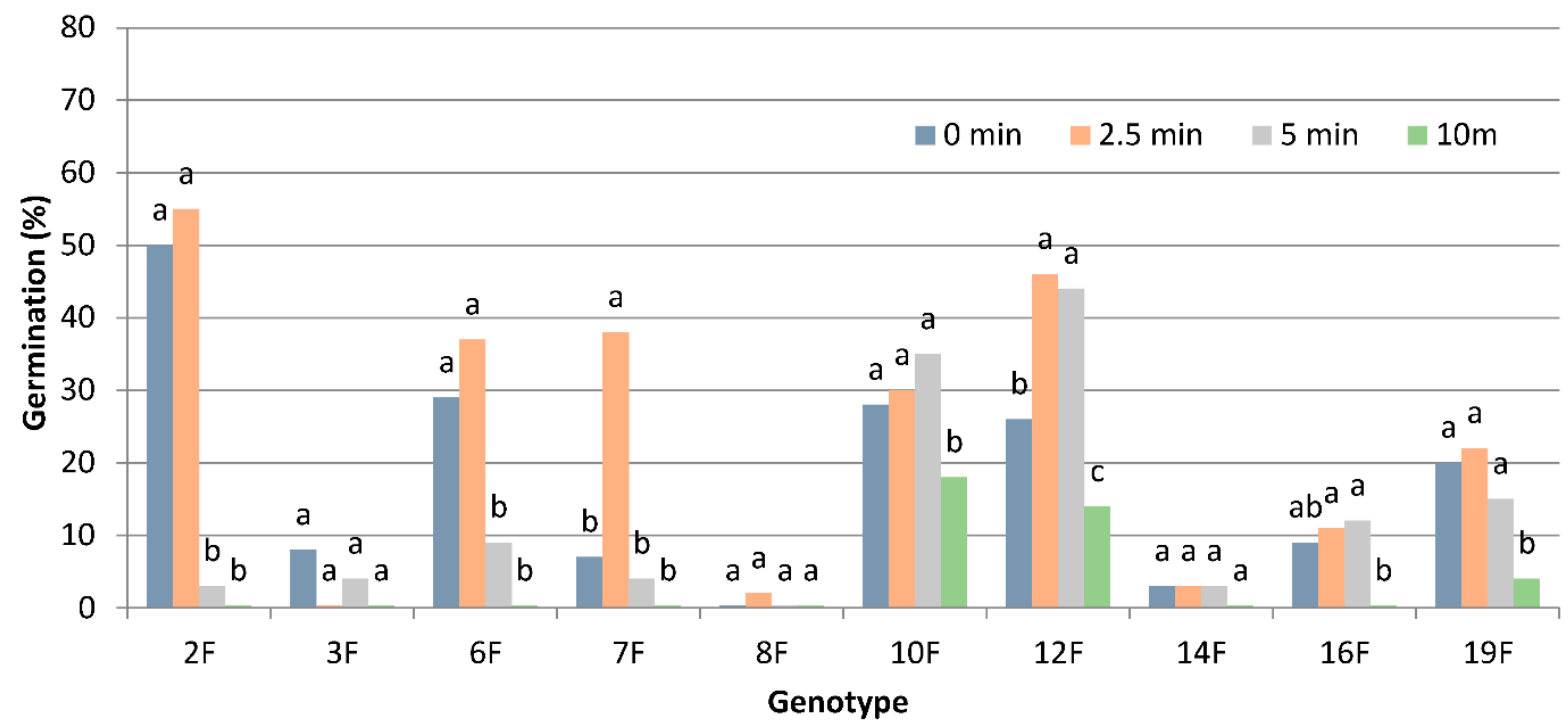

Figure 4. Effect of scarification using $\mathrm{H}_{2} \mathrm{SO}_{4}$, at different time-durations (2.5, 5 or $10 \mathrm{~min}$ ), on seed germination of ten genotypes of $P$. lentiscus var. Chia, three weeks from the sowing day. Different letters in each genotype indicate statistically significant differences according to Duncan's multiple range test at $p \leq 0.05$.

The treatment with $\mathrm{H}_{2} \mathrm{SO}_{4}$ of the seeds for 10 min resulted in a significant reduction of the number of germinated seeds in the genotypes 10F, 12F and 19F, while in the other seven genotypes, it inhibited their seed germination. Possibly, the prolonged duration of $\mathrm{H}_{2} \mathrm{SO}_{4}$ treatment caused the loss of seed viability. In the genotypes $3 \mathrm{~F}, 8 \mathrm{~F}$ and $14 \mathrm{~F}$, where no effect of scarification with $\mathrm{H}_{2} \mathrm{SO}_{4}$ on seed germination was observed, the germination percentages were very low (ranged from 2 to $8 \%$ ). Seed abortion and parthenocarpy are the main causes for the low percentages of germination in P. lentiscus species. Mulas et al. [16], studying 33 female individuals of $P$. lentiscus, found significant differences among them concerning the germination percentage and the speed of germination. Specifically, the seed germination percentages ranged from 0 to $56 \%$ and in 15 individuals out of 33 , no germination occurred. It is obvious that the selection of genotypes with a high percentage of seed germination is very important for the sexual propagation of P. lentiscus var. Chia.

In the second experiment, the collection period did not affect the percentage of germinated seeds in 2F, 3F, 7F, 8F, 14F, 16F and 19F genotypes of the mastic tree (Figure 5). In the genotypes, $6 \mathrm{~F}$ and $10 \mathrm{~F}$, the seeds collected on 15 January exhibited the lowest germination percentage, whereas no significant differences were observed in the germination percentage between the other two collection periods. In contrast, the seeds of the genotype $12 \mathrm{~F}$, which were collected on 15 October, exhibited the lowest germination percentage, whereas no significant differences were found between the other two collection periods in the germination percentage (Figure 5).

The findings of this work showed that there was great heterogeneity in seed germination among the P. lentiscus var. Chia genotypes tested. This corroborates the fact that the selection of the genotype is an important factor for the sexual propagation of $P$. lentiscus var. Chia plants. Furthermore, the scarification using $\mathrm{H}_{2} \mathrm{SO}_{4}$ for $2.5 \mathrm{~min}$ was found to have a positive effect on seed germination for some genotypes and neutral for others. As far as the collection time-period is concerned, this factor did not seem to have much significance on the seed germination, at least in certain genotypes, while in some others, it was found that the seed collection in winter (January) had a negative effect. Figure $1 \mathrm{H}$ shows young plantlets produced from germinated seeds of P. lentiscus var. Chia. 


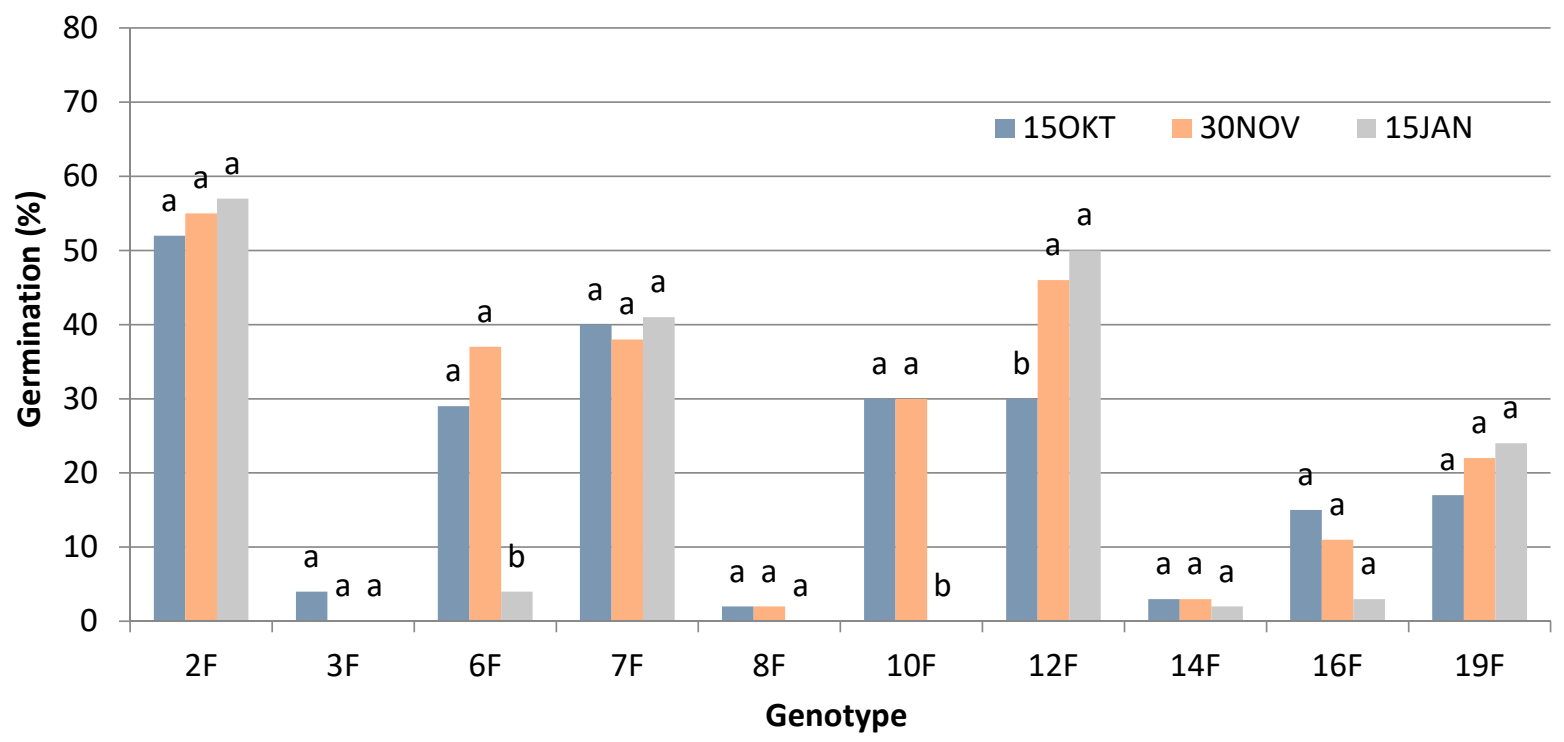

Figure 5. Effect of different time-periods of seed harvesting (15 October, 30 November or 15 January) on germination of ten female genotypes of $P$. lentiscus var. Chia, three weeks from the day of sowing. Different letters in each genotype indicate statistically significant differences according to Duncan's multiple range test at $p \leq 0.05$.

\subsection{Morphological Analysis of the Traits}

In most of the recorded morphological traits of the plants, a significant variation was observed among the 20 examined genotypes of $P$. lentiscus var. Chia grown in the Island of Chios, while for other traits, several similarities were noticed. A first observation was that there were no significant differences between male and female plants. A detailed presentation of the measurements of the traits is given in the Supplementary Table S5. For the trait of "growth habit", all genotypes were evaluated as "spreading". The genotypes $8 \mathrm{~F}$ and $6 \mathrm{~F}$ had the biggest composite leaves as concerned their "length" and "width", while the genotypes 2F, 16F and 19F had the smallest ones (Figure 6A,B). For the trait of "number of leaflets", the genotype 6M had 7.5 leaflets and differed significantly from the other genotypes, while the lowest values were observed in the genotypes $7 \mathrm{~F}, 15 \mathrm{M}$ and $36 \mathrm{M}$ (Figure 6C). The "terminal leaflets length" was bigger in the genotypes 6F and 15M than in the other genotypes, while the genotype $15 \mathrm{M}$ also had the biggest "terminal leaflets width" (Figure 6D,E). The traits of the "terminal leaflets shape", "terminal leaflets apex," and "terminal leaflets base" were different among the genotypes without any correlation with the plant gender (Table S5). There were differences among the genotypes for the traits of "plant height" and "plant diameter", basic elements that are interested in gardening as they affect the shape of the canopy of the tree. Finally, for the traits of "fruit yielding" and "seed size", characteristics measured in female plants, there were found significant differences (Table S5). 

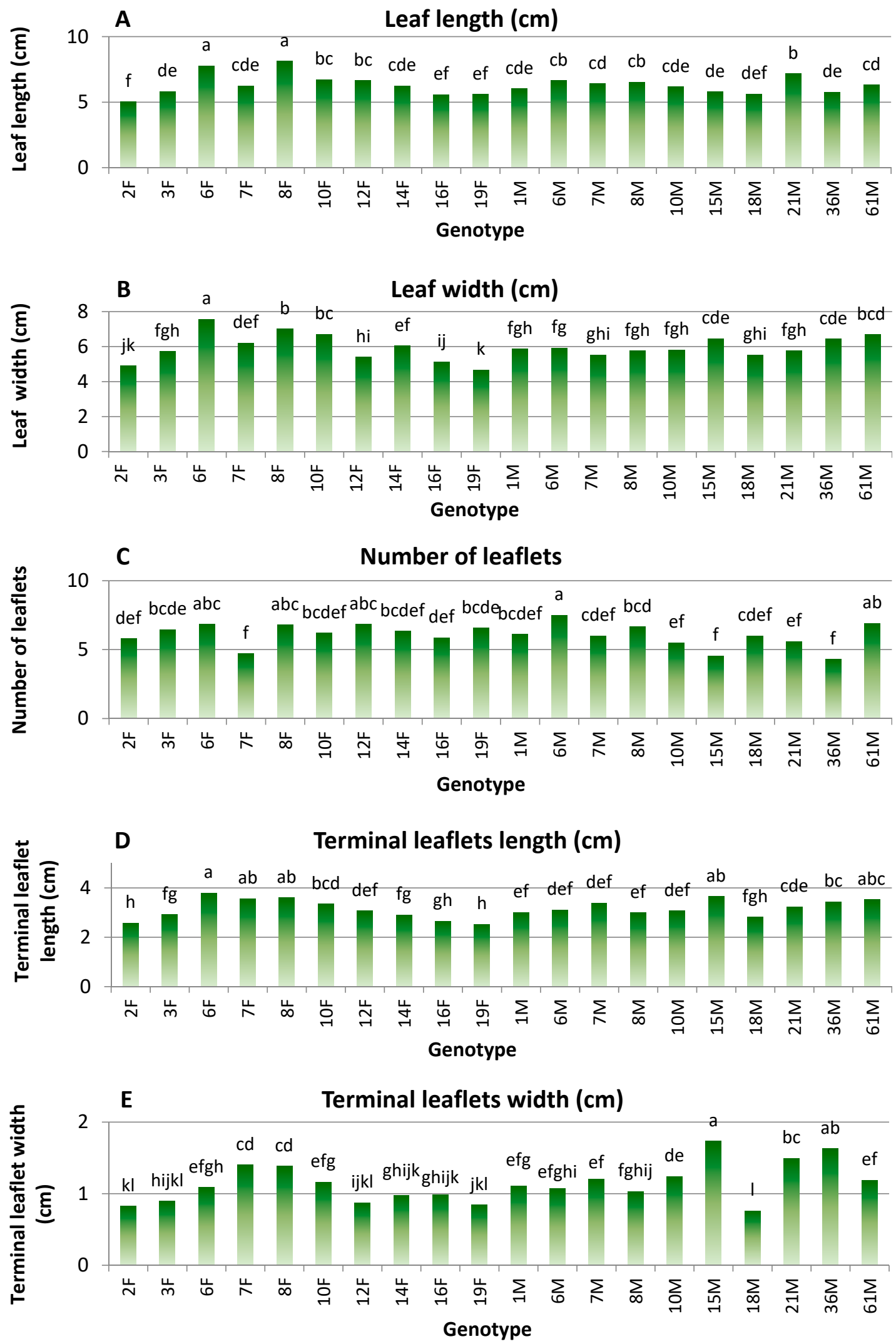

Figure 6. Mean values for 5 out of 13 morphological traits of ornamental interest [leaf length (cm), leaf width (cm), number of leaflets, terminal leaflets length $(\mathrm{cm})$ and terminal leaflets width $(\mathrm{cm})]$ measured on the 20 selected genotypes of $P$. lentiscus var. Chia. The means of the remaining 8 traits are presented in the Supplementary Table S5. Different letters in columns for each of the traits indicate statistically significant differences according to Duncan's multiple range test at $p \leq 0.05$. 
Subsequently, the recorded morphological data were matched with those of the male genotypes of $P$. lentiscus var. Chia belonging to the local cultivars of 'Mavroschinos' (MV), 'Psilophyllos' (PS), 'Maroulitis' (ML), 'Platiphyllos' (PL) and 'Votomos' (V). In 'Mavroschinos', the main morphological characteristics are the dark-gray color of the tree branches (trait not recorded) and the medium size of the leaflets with a sharp angle to the edge. The genotypes $1 \mathrm{M}$ and $6 \mathrm{M}$, which both belong to 'Mavroschinos', had mediumsize leaflets. In relation to the other studied morphological traits, the genotypes $1 \mathrm{M}$ and $6 \mathrm{M}$ did not have statistically significant differences except for the "number of leaflets", "terminal leaflets apex" and "terminal leaflets base", as shown in the Supplementary Table S5. 'Psilophyllos' is distinguished by the other cultivars for its small leaflets, and for this reason is called 'Psilophyllos', which means "small leaf" (Figure 7). Consequently, the "terminal leaflets length" and "terminal leaflets width" of the genotypes 8M and 18M, which belong to 'Psilophyllos', had the smallest values among the male genotypes, while in the other traits, there were no differences between them except for the "terminal leaflets apex", "terminal leaflets base", "plant height" and "plant diameter". Regarding the genotypes 7M and 61M of 'Votomos', significant differences were observed for the traits of the "leaf width", "terminal leaflets length", and "plant height" and similarities for the others. The other two cultivars, 'Platiphyllos' and 'Maroulitis', are characterized for their large leaflets with differences, however, between them (Figure 7). In 'Maroulitis', the leaflet is of heart-shape at the edge, while 'Platiphyllos' (which means "wide leaf") has the widest leaflets and the fewest leaflets per compound leaf. The measurements of the traits confirmed the morphological characteristics of the plants as the genotypes $15 \mathrm{M}$ and $36 \mathrm{M}$ of 'Platiphyllos' had the largest "terminal leaflets width", but the smaller "number of leaflets" per composite leaf than the other genotypes (Table S5). The "terminal leaflet apex" of the genotypes 10M and 21M, belonging to 'Maroulitis', is heart-shaped (Figure 7, Table S5). From the above, it appears that despite the apparent uniformity among the cultivars, in their main traits, there were significant differences for many of them. Thus, for an in-depth study of the phenotypic variability that existed among the cultivars of P. lentiscus var. Chia, more traits should be studied in a larger number of individual plants.

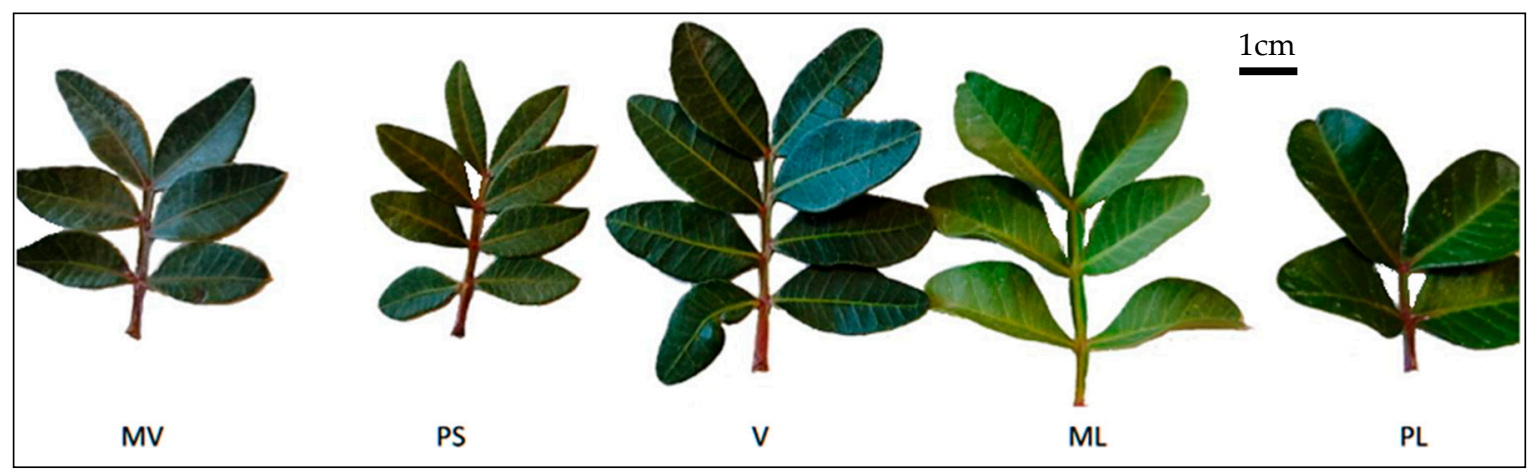

Figure 7. Composite leaves of the five cultivars 'Mavroschinos' (MV), 'Psilophyllos' (PS), 'Votomos' (V), 'Maroulitis' (ML) and 'Platiphyllos' (PL) of P. lentiscus var. Chia.

Regarding the traits that are of interest for using P. lentiscus var. Chia as a plant with ornamental properties, these may not be the same for every use in gardening or in landscaping, e.g., the big size of the plant is desirable for a large open area like a park, but not for a small garden. Thus, some desirable traits of $P$. lentiscus var. Chia, which could be exploited in gardening, are plant robustness, small to medium size canopy, slow growth for avoiding frequent pruning, rich foliage, dark-green leaves, etc. In some cases, the presence of red fruits is also desirable, so female plants can be preferred. Combining these properties and according to Supplementary Table S5, the most suitable female genotype for ornamental use is $6 \mathrm{~F}$, a medium-sized plant, which moreover has the biggest values in leaf length, leaf width, number of leaflets and terminal leaflets length. From the male 
genotypes, an option could be genotype $1 \mathrm{M}$, which has the largest leaflets, but the smallest number of leaflets per compound leaf. Additional options are the genotypes $6 \mathrm{M}$ and $61 \mathrm{M}$, plants of medium size and rich foliage.

The results of Pearson's correlation analysis are presented in the Supplementary Table S6. A high correlation level $(p<0.01)$ was determined in a number of pairs of the morphological traits, with the highest correlation $(r=0.917)$ to be between "terminal leaflet length" and "leaf width". In addition, "leaf length" and "leaf width" showed a high correlation $(r=0.702)$. Similarly, Turhan-Serttas and Ozcan [21] recorded the morphological characteristics of P. lentiscus and found high correlation levels among the traits, with the most significant being the pair of "leaf width" and "leaflet size".

\subsection{Genetic Analysis of the Genotypes}

Twenty-one ISSR primers, chosen from the University of British Columbia collection, were tested initially on genomic DNA extracted from 20 P. lentiscus var. Chia genotypes, while only eight of them gave reproducible and clear results and therefore were selected for use (Table 4 and Table S2). Hence, these eight primers resulted in the generation of multiple banding patterns (Table 4, Figure 8). The number of amplified bands ranged from 14 (primer UBC 818) to 27 (primers UBC 807 and UBC 811). The total number of bands produced using the eight ISSR primers was 3260, and 2700 of them were polymorphic, accounting for a polymorphism of $83.50 \%$ (Table 4 ). The markers had an average number of polymorphic bands of 16.87 per primer and were used to detect the relationship among the 20 genotypes.
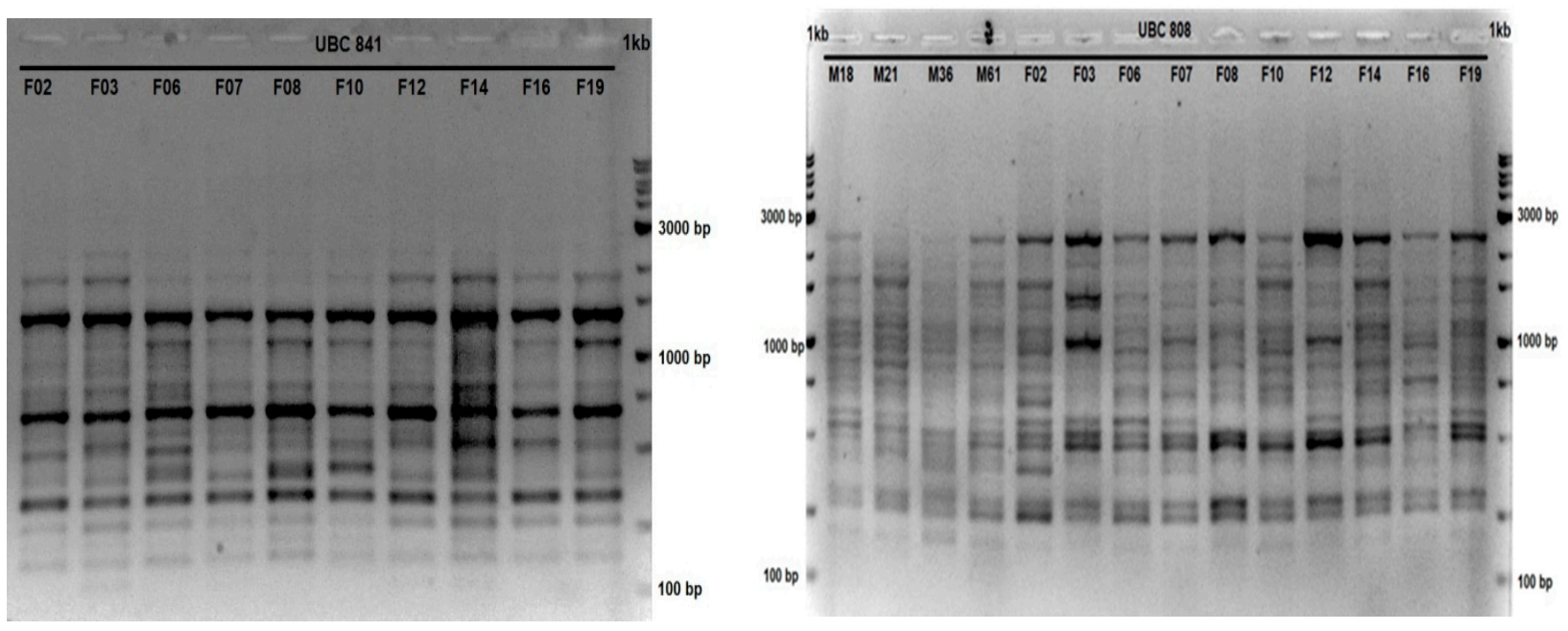

Figure 8. Representative gel electrophoretic pattern of the amplification reactions performed using DNA from $P$. lentiscus var. Chia genotypes (F2 to F19 and M18 to F19) and primers UBC 841 and UBC 808. The size of the amplified zones was calculated using $1 \mathrm{~kb}$ DNA ladder plus. 


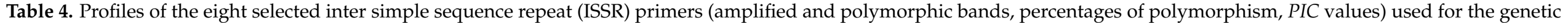
analysis of the 20 genotypes of $P$. lentiscus var. Chia.

\begin{tabular}{|c|c|c|c|c|c|c|c|c|}
\hline Primer & Sequence & $\mathbf{N t}$ & $\operatorname{Tm}\left({ }^{\circ} \mathrm{C}\right)$ & Size Min-Max (bp) & $\begin{array}{c}\text { No. of } \\
\text { Amplified Bands }\end{array}$ & $\begin{array}{c}\text { No. of } \\
\text { Polymorphic Bands }\end{array}$ & Polymorphic Ratio & PIC \\
\hline UBC 807 & AGAGAGAGAGAGAGAGT & 17 & 50.4 & $50-3230$ & 27 & 20 & $74 \%$ & 0.27 \\
\hline UBC 808 & AGAGAGAGAGAGAGAGC & 17 & 52.8 & $250-2440$ & 17 & 13 & $76 \%$ & 0.26 \\
\hline UBC 811 & GAGAGAGAGAGAGAGAC & 17 & 52.8 & $130-2290$ & 27 & 23 & $85 \%$ & 0.31 \\
\hline UBC 818 & CACACACACACACACAG & 17 & 52.8 & $180-1350$ & 14 & 14 & $100 \%$ & 0.35 \\
\hline UBC 827 & ACACACACACACACACG & 17 & 52.8 & $270-2370$ & 16 & 12 & $75 \%$ & 0.26 \\
\hline UBC 834 & GAGAGAGAGAGAGAGAYT & 18 & 52.6 & $240-2280$ & 18 & 18 & $100 \%$ & 0.40 \\
\hline UBC 841 & GAGAGAGAGAGAGAGAYC & 18 & 54.8 & $110-2370$ & 19 & 14 & $74 \%$ & 0.26 \\
\hline UBC 856 & ACACACACACACACACYA & 18 & 52.5 & $220-3300$ & 25 & 21 & $84 \%$ & 0.29 \\
\hline
\end{tabular}


According to the ISSR assay, the average PIC value was calculated as 0.30 . When polymorphism is at a high-level PIC value is $>0.5$, while if it is between 0.25 and 0.5 , as in the present study, the polymorphism is normal [35]. The PIC values ranged from 0.26 to 0.40 , and according to these values, the most informative markers were UBC 834 and UBC 818 (Table 4). The PCoA-ISSR data showed that $22.51 \%$ of the variation is explained by the coordinates 1 and 2, with the first coordinates explaining 12.62\% and the second one $9.89 \%$ of total variation (Figure 9 ). The ten female and the ten male P. lentiscus var. Chia genotypes were segregated in the PCoA. Although the female genotypes are in the red circle and the males in the blue circle, some genotypes ( $1 \mathrm{M}$ and $2 \mathrm{~F})$ belonged to both circles, indicating that there was an area in the center of the PCOA where plants cannot be separated into males and females. In addition, the ISSR marker-based PCoA results showed that the female genotypes 10F, 12F, 14F, 16F, 19F fell into the same subpopulation and $6 \mathrm{~F}, 7 \mathrm{~F}, 8 \mathrm{~F}$ into another one, while the male genotypes were more scattered in the PCoA space and cannot be divided into subpopulations (Figure 9).

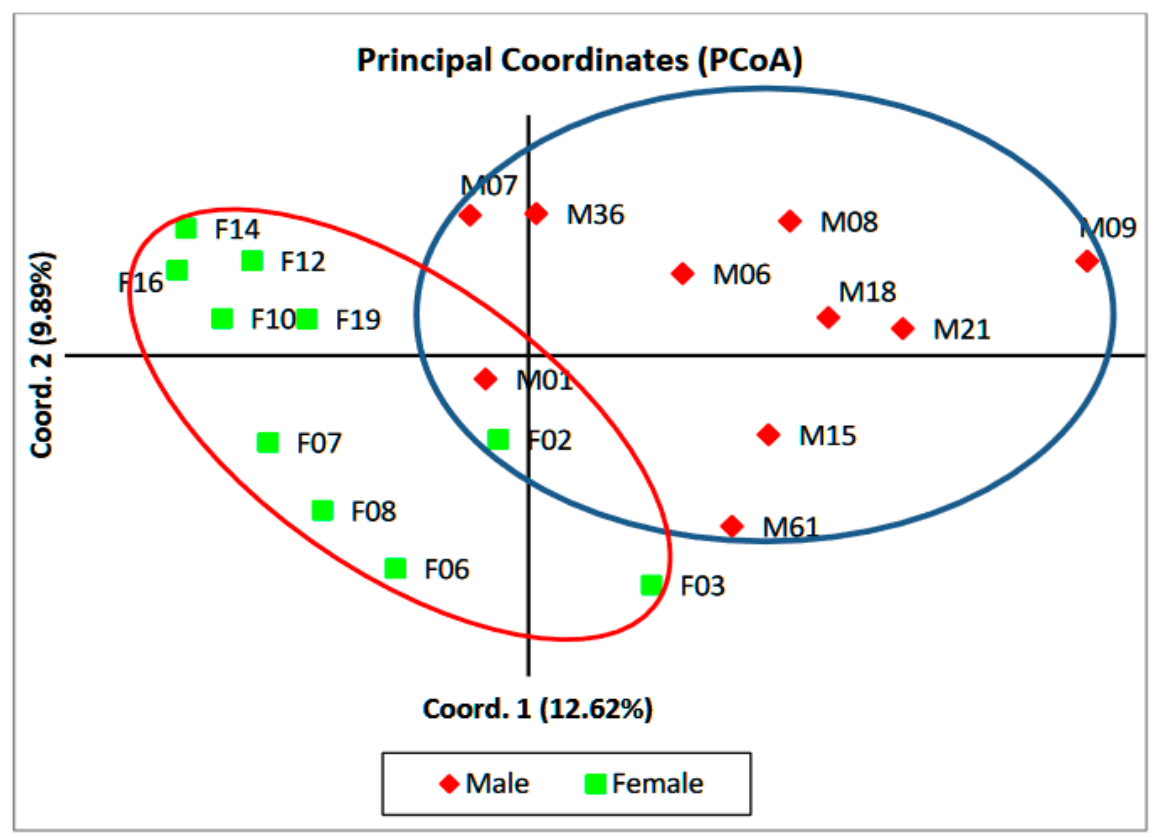

Figure 9. Principal coordinates analysis (PCoA) derived from bands amplified by eight ISSR primers among the 20 P. lentiscus var. Chia genotypes, ten female and ten male, from Chios Island.

Similar results were observed in the presentation of the data of the amplified DNA bands in the form of a dendrogram, where the 20 P. lentiscus var. Chia genotypes clustered into four groups: in two major clusters containing eight female and eight male genotypes (Figure 10, Group 1 and Group 2, respectively), in one smaller cluster containing two female and one male genotype (Figure 10, Group 3) and in a fourth group consisting of a single male genotype (Figure 10, Group 4). These findings showed that in this case, no complete separation between male and female individuals could be made, as the female and male genotypes $3 \mathrm{~F}, 61 \mathrm{M}$ and $2 \mathrm{~F}$ clustered in the same group, while $15 \mathrm{M}$ constitutes a separate group. Thus, the conclusion that may arise is that the particular set of ISSR markets may be used to discriminate most, but not all, male plants from female ones. The results are, in part, contradictory to the ones of Abuduli et al. [20], who also separated the male and female genotypes using ISSRs. In their study, ISSR markers indicated that 24 P. lentiscus genotypes mainly from Turkey were segregated into five major groups, two of which included exclusively female plants, while the remaining three groups contained only male genotypes. This may be due to the fact that in this study, the authors used plant material originating almost exclusively from Turkey, except for just one sample originating from Chios Island. In the present study, the plant material originated solely from Chios 
Island. In another study, Zografou et al. [19] separated male and female genotypes of $P$. lentiscus from Chios, but in this case, only one female genotype was used, and therefore, no safe conclusion can be drawn.

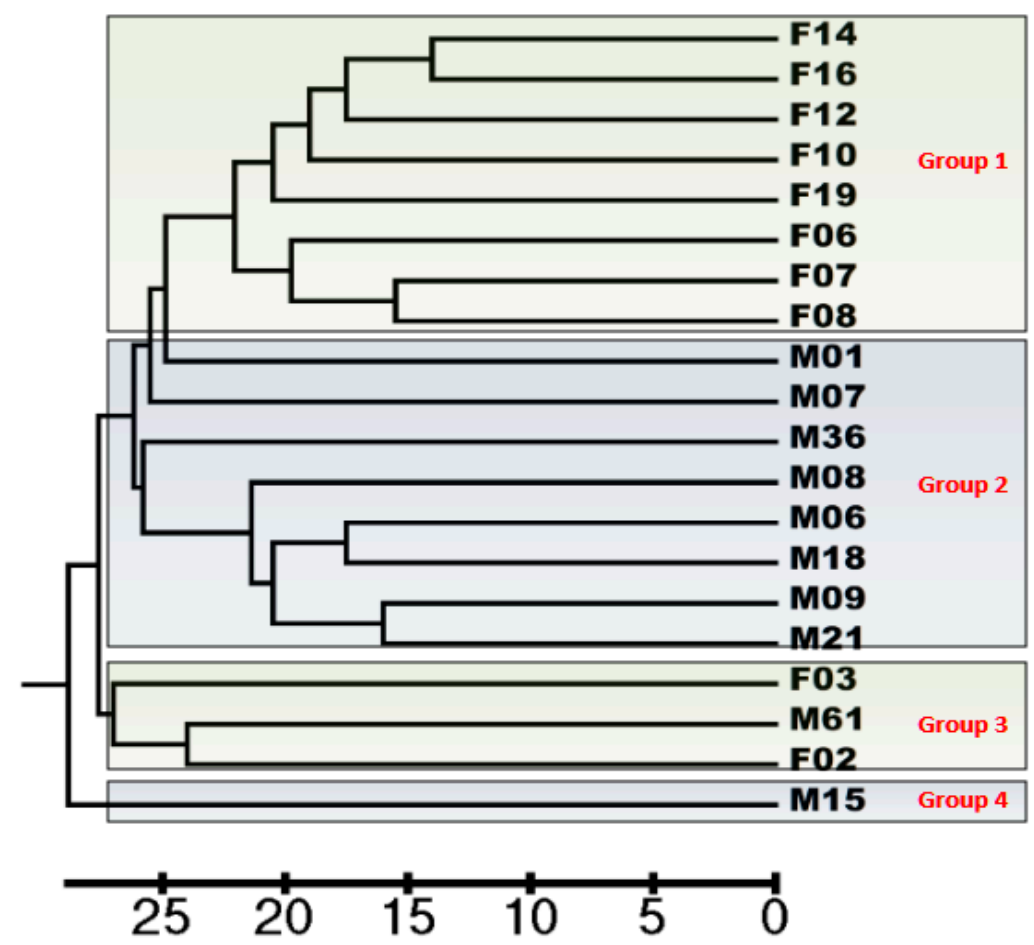

Figure 10. Dendrogram based on Nei [31] standard genetic distance using UPGMA method generated by eight ISSR primers among $20 \mathrm{P}$. lentiscus var. Chia genotypes, ten female and ten male, from Chios Island.

The data from the ISSR molecular markers analysis of the ten males of P. lentiscus var. Chia genotypes were also used separately to determine the genetic distance among them. These data were recorded in a dendrogram to determine whether our results of the genetic analysis were in agreement with the results of the phenotypic measurements that identify the cultivars of P. lentiscus var. Chia ['Mavroschinos' (MV), 'Psilophyllos' (PS), 'Maroulitis' (ML), 'Platiphyllos' (PL) and 'Votomos' (V)]. To this end, the names of genotypes were converted from $1 \mathrm{M}, 6 \mathrm{M}, 7 \mathrm{M}, 8 \mathrm{M}, 10 \mathrm{M}, 15 \mathrm{M}, 18 \mathrm{M}, 21 \mathrm{M}, 36 \mathrm{M}$ and $61 \mathrm{M}$, to MV1, MV6, V7, PS8, ML10, PL15, PS18, ML21, PL36 and V61, respectively, in order to facilitate their presentation in the figure. The results of the dendrogram (Figure 11) separated the genotypes into three different groups. Groups 1 and 2 include genotypes belonging to different morphological cultivars: Group 1 contains genotypes belonging to 'Mavroschinos', 'Psilophyllos' and 'Maroulitis', while group 2 includes members of 'Platiphyllos', 'Votomos' and 'Mavroschinos'. Group 3 consists of a single plant belonging to the cultivar 'Platiphyllos'. These findings establish the existence of genetic heterogeneity in most morphological cultivars and are in partial agreement with the results of Zografou et al. [19], who used RAPD and ISSR analysis on 11 plants (ten male and one female) and reported that the cultivars were separated genetically, but the members of the cultivars were not genetically homogeneous. In order to better understand the genetic classification of $P$. lentiscus var. Chia, more genotypes should be examined, and more markers should be applied so that a safe conclusion can be drawn from the analysis of the data. 


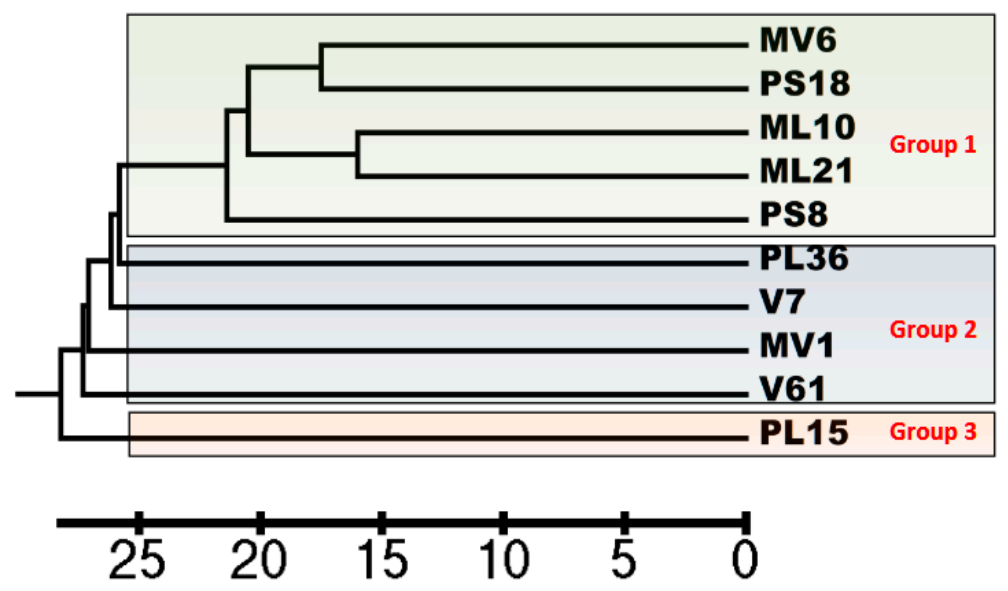

Figure 11. Dendrogram of ten male P. lentiscus var. Chia genotypes ['Mavroschinos' (MV), 'Psilophyllos' (PS), 'Maroulitis' (ML), 'Platiphyllos' (PL) and 'Votomos' (V)] from Chios Island based on ISSR data using the UPGMA method.

\subsection{Correlation of Morphological Traits with ISSR Markers}

Multiple regression analysis (MRA) was applied to estimate the relationships among some morphological traits of the 20 P. lentiscus var. Chia genotypes with the ISSR bands. In MRA, the ISSR markers were independent variables and showed significantly positive or negative correlations with dependent variables, the morphological traits (Table 5). Five bands were diagnosed to be affiliated with the trait of "terminal leaflet length". Four of them encompassing the UBC $841_{440}, \mathrm{UBC} 856_{320}, \mathrm{UBC} 811_{130}$ and UBC $856_{1340}$ had a positive correlation, whereas the UBC $808_{750}$ had a negative correlation. High beta and $t$ values, which are interpreted with a higher marker-trait correlation, were observed in the UBC $841_{440}$ band with values of 0.531 and 6.253 , respectively. In the trait of "number of leaflets" probability, $85.7 \%\left(R^{2}=0.857\right)$ occurred with the presence of the bands UBC $856_{3300}$ and UBC $834_{720}$ and the absence of the UBC $827_{980}$ and UBC856 260 . The highest value of the beta coefficient was observed in the marker UBC $827_{980}$, which had the highest value of $t=-7.467$ compared to the other markers (Table 5). A negative sign for the UBC $827_{980}$ means that there was an inverse correlation between the marker and the "number of leaflets", so the absence of the band enables high prices in this trait. A combination of five markers accounted for up to $98.6 \%$ of the variation in the trait of "terminal leaflet apex". Three of these markers were linked positively and two negatively with this trait and showed a highly significant correlation, especially for the ISSR marker UBC $841_{730}$ with the most important beta coefficient value $(\beta=0.459), P$ and $t$ values $(p<0.000, t=5.233)$. In addition, for the P. lentiscus var. Chia gender, a $97.2 \%\left(R^{2}=0.972\right)$ probability was detected by the presence of the band $\mathrm{UBC} 811_{250}$ and the absence of the bands UBC $841_{2370}$, UBC $856_{570}$, UBC $808_{1350}$ and UBC $808_{750}$. The most important from these bands was the UBC $841_{2370}$, which had a negative correlation with this trait of beta coefficient 0.048 and $t=-0.763$. Finally, a correlation was observed between the absence of ISSR band UBC $834_{1490}$ and the presence of UBC $827_{680}$ and $\mathrm{UBC} 807_{600}$ and the rooting of shoot cuttings with $8 \mathrm{~g} \cdot \mathrm{L}^{-1} \mathrm{~K}-\mathrm{IBA}$. The combination of these markers provides high rooting possibilities $\left(95.6 \%, R^{2}=0.956\right)$ with this manipulation, while the most important marker was UBC $834_{1490}$ with standardized beta coefficients -1.081 and $t$ value -11.348 (Table 5). There have been no previous studies in P. lentiscus var. Chia that have detected correlations between morphological traits and ISSR markers. However, there are reports for other species, like mulberry and cherry, where correlations have been found between ISSR markers and morpho-physiological traits $[38,39]$. 


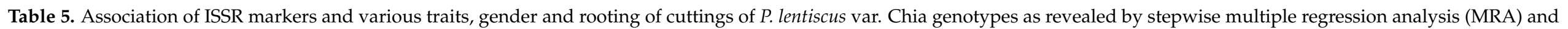
coefficients.

\begin{tabular}{|c|c|c|c|c|c|c|c|}
\hline & $\begin{array}{l}\text { ISSR Markers } \\
\text { (alleles) }\end{array}$ & $r$ & $R^{2}$ & $\begin{array}{l}\text { Standard } \\
\text { Error }\end{array}$ & $\begin{array}{l}\text { Standardized Beta } \\
\text { Coefficients }\end{array}$ & $t$ Value & $p$ Value \\
\hline \multirow{5}{*}{$\begin{array}{c}\text { Terminal leaflets } \\
\text { length }\end{array}$} & UBC $841_{440}$ & 0.717 & 0.514 & 0.072 & 0.531 & 6.253 & 0.000 \\
\hline & $+\mathrm{UBC} 86_{320}$ & 0.840 & 0.706 & 0.056 & 0.302 & 3.982 & 0.001 \\
\hline & + UBC808 750 & 0.894 & 0.799 & 0.063 & -0.393 & -5.021 & 0.000 \\
\hline & $+\mathrm{UBC} 811_{130}$ & 0.940 & 0.884 & 0.090 & 0.252 & 3.423 & 0.004 \\
\hline & +UBC $856_{1340}$ & 0.967 & 0.935 & 0.059 & 0.254 & 3.300 & 0.005 \\
\hline \multirow{4}{*}{ Number of leaflets } & UBC827980 & 0.509 & 0.259 & 0.188 & -0.790 & -7.467 & 0.000 \\
\hline & +UBC856 3300 & 0.671 & 0.451 & 0.413 & 0.702 & 6.354 & 0.000 \\
\hline & $+\mathrm{UBC} 834_{720}$ & 0.861 & 0.741 & 0.166 & 0.542 & 5.356 & 0.000 \\
\hline & $+\mathrm{UBC} 856_{260}$ & 0.926 & 0.857 & 0.164 & -0.352 & -3.491 & 0.003 \\
\hline \multirow{5}{*}{ Terminal leaflets apex } & UBC $811_{250}$ & 0.566 & 0.320 & 0.257 & 0.367 & 3.577 & 0.003 \\
\hline & +UBC841 730 & 0.760 & 0.578 & 0.253 & 0.459 & 5.233 & 0.000 \\
\hline & $+\mathrm{UBC} 818_{330}$ & 0.862 & 0.743 & 0.269 & -0.330 & -3.829 & 0.002 \\
\hline & +UBC811 1450 & 0.914 & 0.836 & 0.329 & 0.414 & 4.397 & 0.001 \\
\hline & $+\mathrm{UBC} 841_{570}$ & 0.949 & 0.901 & 0.306 & -0.322 & -3.038 & 0.009 \\
\hline \multirow{5}{*}{ Gender } & UBC841 2370 & 0.734 & 0.538 & 0.048 & -0.763 & -16.543 & 0.000 \\
\hline & $+\mathrm{UBC} 86_{570}$ & 0.863 & 0.744 & 0.053 & -0.537 & -11.149 & 0.000 \\
\hline & +UBC808 1350 & 0.929 & 0.863 & 0.052 & -0.323 & -6.786 & 0.000 \\
\hline & $+\mathrm{UBC} 811_{250}$ & 0.974 & 0.949 & 0.049 & 0.356 & 7.286 & 0.000 \\
\hline & +UBC808 750 & 0.986 & 0.972 & 0.056 & -0.172 & -3.378 & 0.005 \\
\hline \multirow{3}{*}{$\begin{array}{l}\text { Rooting of cuttings } \\
\text { with } 8 \mathrm{~g} \cdot \mathrm{L}^{-1} \mathrm{~K}-\mathrm{IBA}\end{array}$} & UBC834 1490 & 0.828 & 0.685 & 2.906 & -1.081 & -11.348 & 0.000 \\
\hline & $+\mathrm{UBC} 827_{680}$ & 0.939 & 0.883 & 2.906 & 0.449 & 4.711 & 0.003 \\
\hline & +UBC807 600 & 0.978 & 0.956 & 2.466 & 0.281 & 3.187 & 0.019 \\
\hline
\end{tabular}




\section{Conclusions}

This study underlined the effectiveness of the K-IBA on the rooting of shoot cuttings in the winter of $P$. lentiscus var. Chia genotypes selected for their ornamental value. The most efficient concentrations proved to be 4 and $8 \mathrm{~g} \cdot \mathrm{L}^{-1}$. Furthermore, scarification of seeds with $\mathrm{H}_{2} \mathrm{SO}_{4}$ for 2.5 min increased the percentage of germination in two genotypes (7F and $12 \mathrm{~F}$ ) and accelerated the time of germination in most of them. However, differences were observed among the used genotypes, both for their shoot cuttings rooting and seed germination. The best genotype based on rooting ability was $8 \mathrm{M}(62.5 \%)$, while based on seed germination, the most prolific genotype was $2 \mathrm{~F}(57 \%)$. From the standpoint of exploiting the morphological traits for ornamental use, the genotype $3 \mathrm{~F}$ (female) had the largest leaves with a good medium size canopy (bearing red fruits) suitable for gardening and fair cutting rooting (27.5\%) and seed germination (37\%). From the male plants, the genotype $61 \mathrm{M}$ had a medium size canopy with dense foliage and a high rooting capacity of its shoot cuttings (52.5\%). ISSR markers used in the present study separated the examined genotypes into four groups, one group consisting exclusively of male, one of female, one consisting of members from both genders and a fourth containing a single male genotype. Furthermore, the results indicated correlations between the traits of "terminal leaflets length" and "leaf width" and between bands of the ISSR markers and the traits of "terminal leaflets length", "number of leaflets", "terminal leaflets apex", the "gender" and the "rooting of cuttings with $8 \mathrm{~g} \cdot \mathrm{L}^{-1} \mathrm{~K}-\mathrm{IBA}$ ". These correlations could be exploited as tools for future breading of $P$. lentiscus var. Chia for ornamental use.

Supplementary Materials: The following are available online at https:/ /www.mdpi.com/2073-439 5/11/2/205/s1, Figure S1: Map of Southern Chios Island presenting the geographical locations of the selected ten female (F) and ten male (M) genotypes of P. lentiscus var. Chia. Table S1: Detailed description of the morphological traits that were measured on 20 selected genotypes of $P$. lentiscus var. Chia focused on properties that were mainly related to the appearance of the trees and their ornamental value. Table S2: Profiles of the 21 ISSR primers initially used for the genetic analysis of the 20 genotypes of $P$. lentiscus var. Chia, while finally the first 8 were used and the rest 13 were rejected as unsuitable. Table S3: Rooting (\%) of shoot cuttings of ten male and ten female genotypes of P. lentiscus var. Chia, in winter, with the application of different concentrations of K-IBA. Table S4: Recording of seed germination (\%) at weekly intervals of ten genotypes (female) of P. lentiscus var. Chia, after the application of $\mathrm{H}_{2} \mathrm{SO}_{4}$ scarification for $0,2.5,5$ or $10 \mathrm{~min}$ of duration on seeds harvested on 30 November $(n=100)$. Table S5: Measurements of morphological traits from 20 selected genotypes of $P$. lentiscus var. Chia focused on properties that were mainly related to the appearance of the trees and their ornamental value. In the case of traits 1 and 10-12, a value based on personal experience and observation was determined. The values in cases 2-9 were average measurements of 20 leaves, collected at the adult stage from each one of the plants. Table S6: Pearson's correlation tests among 10 main morphological traits of $P$. lentiscus var. Chia.

Author Contributions: S.K., S.H., E.P., E.H. and A.E. conceptualized the study. S.K., S.H., E.P., V.A., F.-T.Z. and A.K. conducted the experiments of shoot rooting and seed germination. E.H., A.V., P.M. and A.-S.A. conducted the experiments of ISSR molecular markers. I.S., T.V. and M.C. conducted the experiments of morphological traits. S.K. and S.H. conducted the statistical analysis. S.K., S.H. and A.E. wrote the manuscript. S.K., S.H., E.H. and A.E. edited the manuscript. S.K., S.H., E.H. and A.E. critically revised the draft and updated the manuscript for publication. All authors have read and agreed to the published version of the manuscript.

Funding: Financial support for this study was provided by the "RESEARCH—CREATE-INNOVATE" funded by the Operational Programme Competitiveness, Entrepreneurship and Innovation 2014-2020 (EPAnEK) (grant no. T1EDK-01133), with the co-financing of Greece and the European Union.

Institutional Review Board Statement: Not applicable.

Informed Consent Statement: Not applicable.

Data Availability Statement: Data sharing not applicable.

Acknowledgments: The technical assistance of Marianna Aggelaki is gratefully acknowledged. 
Conflicts of Interest: The authors declare no conflict of interest.

$\begin{array}{ll}\text { Abbreviations } \\ \text { AFLP } & \text { Amplified fragment length polymorphism } \\ \text { GA }_{3} & \text { Gibberellic acid } \\ \text { gDNA } & \text { Genomic DNA } \\ \text { IRAP } & \text { Inter-retrotransposon amplified polymorphism } \\ \text { ISSR } & \text { Inter simple sequence repeat } \\ \text { ITS } & \text { Internal transcribed spacer } \\ \text { K-IBA } & \text { Potassium salt of indolebutyric acid } \\ \text { MRA } & \text { Multiple regression analysis } \\ \text { PCoA } & \text { Principal coordinates analysis } \\ \text { PCR } & \text { Polymerase chain reaction } \\ \text { PIC } & \text { Polymorphism information content } \\ \text { RAPD } & \text { Random amplified polymorphic DNA } \\ \text { SSR } & \text { Simple sequence repeat } \\ \text { UPGMA } & \text { Unweighted paired group method analysis }\end{array}$

\section{References}

1. Al-Saghir, M.G.; Porter, D.M. Taxonomic revision of the genus Pistacia L. (Anacardiaceae). Am. J. Plant Sci. 2012, 3, 12-32. [CrossRef]

2. Bozorgi, M.; Memariani, Z.; Mobli, M.; Salehi-Surmaghi, M.H.; Shams-Ardekani, M.R.; Rahimi, R. Five Pistacia species (P. vera, P. atlantica, P. terebinthus, P. khinjuk and P. lentiscus): A review of their traditional uses, phytochemistry, and pharmacology. Sci. World J. 2013, 2013, 219815. [CrossRef] [PubMed]

3. Boratynski, A.; Browicz, K.; Zielinski, J. Chorology of Trees and Shrubs in Greece; Institute of Dendrology, Polish Academy of Sciences: Kornik, Poland, 1992; p. 286.

4. Browicz, K. Pistacia lentiscus cv. Chia (Anacardiaceae) on Chios Island. Plant Syst. Evol. 1987, 155, 189-195. [CrossRef]

5. Papada, E.; Kaliora, A.C. Antioxidant and anti-inflammatory properties of mastiha: A review of preclinical and clinical studies. Antioxidants 2019, 8, 208. [CrossRef] [PubMed]

6. Tzani, A.; Doulamis, I.P.; Konstantopoulos, P.; Tzivras, D.; Perrea, D.N. Chios mastic gum, the natural "tears" with lipid-lowering and anti-atherosclerotic properties: A new drug candidate? Hell. J. Atheroscler. 2018, 9, 1-4.

7. Alvarez, S.; Rodriguez, P.; Broetto, F.; Sanchez-Blanco, M.J. Long term responses and adaptive strategies of Pistacia lentiscus under moderate and severe deficit irrigation and salinity: Osmotic and elastic adjustment, growth, ion uptake and photosynthetic activity. Agric. Water Manag. 2018, 202, 253-262. [CrossRef]

8. Cristiano, G.; De Mastro, G.; Fracchiolla, M.; Lasorella, C.; Tufarelli, V.; De Lucia, B.; Cazzato, E. Morphological characteristics of different mastic tree (Pistacia lentiscus L.) accessions in response to salt stress under nursery conditions. J. Plant Sci. 2016, $11,75-80$

9. Mascarello, C.; Fascella, G.; Zizzo, G.V.; Mantovani, E.; Ruffoni, B. In vivo and in vitro propagation of Pistacia lentiscus L. Acta Hortic. 2007, 764, 299-306. [CrossRef]

10. Macdonald, B. Practical Woody Plant Propagation for Nursery Growers; Timber Press: Portland, OR, USA, $2006 ;$ p. 669.

11. Piotto, B.; Bartolini, G.; Bussotti, F.; Asensio, A.A.C.; Garcia, C.; Chessa, I.; Ciccarese, C.; Ciccarese, L.; Crosti, R.; Cullum, F.J.; et al. Fact sheets on the propagation of Mediterranean trees and shrubs from seed. In Seed Propagation of Mediterranean Trees and Shrubs; Piotto, B.; Di Noi, A., Eds.; APAT: Roma, Italy, 2003; pp. 11-51.

12. Piotto, B. Influence of scarification and prechilling on the germination of Pistacia lentiscus. Seed Sci. Technol. 1995, $23,659-663$.

13. Abu-Qaoud, H. Effect of scarification, gibberellic acid and stratification on seed germination of three Pistacia species. An-Najah Univ. J. Res. A 2007, 21, 1-11.

14. Garcia-Fayos, P.; Verdu, M. Soil seed bank, factors controlling germination and establishment of a Mediterranean shrub: Pistacia lentiscus L. Acta Oecol. 1998, 19, 357-366. [CrossRef]

15. Isfendiyaroglu, M. Propagation of Mastic Tree: From Seed to Tissue Culture. In Proceedings of the 4 th International Symposium of Medicinal and Aromatic Plants, Izmir, Turkey, 2-4 October 2018; pp. 209-213.

16. Mulas, M.; Abeltino, P.; Brigaglia, N. Evaluation of Pistacia lentiscus L. genetic resources to select ecotypes having high efficiency in the colonization of marginal lands. Acta Hortic. 1998, 457, 279-286. [CrossRef]

17. Joley, L.E.; Opitz, K.W. Further experience with propagation of Pistacia. Comb. Proc. Intern. Plant Prop. Soc. 1971, $21,67-76$.

18. Kostas, S.; Hatziloukas, E.; Hatzilazarou, S.; Economou, A.S. Efficient vegetative propagation of various clones of mastic tree (Pistacia lentiscus 'Chia') through rooting of shoot cuttings. Acta Hortic. 2019, 1242, 739-742. [CrossRef]

19. Zografou, P.; Linos, A.; Hagidimitriou, M. Genetic diversity among different genotypes of Pistacia lentiscus var. Chia (mastic tree). Options Mediterr. 2010, 94, 159-163. 
20. Abuduli, A.; Aydin, Y.; Sakiroglu, M.; Onay, A.; Ercisli, S.; Uncuoglu, A.A. Molecular evaluation of genetic diversity in wild-type mastic tree (Pistacia lentiscus L.). Biochem. Genet. 2016, 54, 619-635. [CrossRef]

21. Turhan-Serttas, P.T.; Ozcan, T. Variations studied by ISSR and IRAP markers in mastic tree (Pistacia lentiscus L.) from Turkey. Trakya Univ. J. Nat. Sci. 2018, 19, 147-157. [CrossRef]

22. Kafkas, S.; Perl-Treves, R. Interspecific relationships in Pistacia based on RAPD fingerprinting. HortScience 2002, 37, 168-171. [CrossRef]

23. Kafkas, S. Phylogenetic analysis of the genus Pistacia by AFLP markers. Plant Syst. Evol. 2006, 262, 113-124. [CrossRef]

24. Snedecor, G.W.; Cochran, W.C. Statistical Methods, 7th ed.; The Iowa State University Press: Ames, IA, USA, $1980 ;$ p. 507.

25. Klockars, A.; Sax, G. Multiple Comparisons; Sage Publications: Newbury Park, CA, USA, 1986; p. 87.

26. ISTA (International Seed Testing Association). International rules for seed testing. Seed Sci. Technol. 1999, $27,333$.

27. Barone, E.; Padulosi, S.; Van Mele, P. Descriptors for Pistachio (Pistaciavera L.); International Plant Genetic Resources Institute (IPGRI): Rome, Italy, 1997; pp. 20-23.

28. Araújo, F.S.; Pacheco, M.V.; Vieira, F.A.; Ferrari, C.S.; Félix, F.C.; Chagas, K.P.T. ISSR molecular markers for the study of the genetic diversity of Mimosa caesalpiniaefolia Benth. Idesia 2016, 34, 47-52. [CrossRef]

29. Khaled, A.G.A.; Motawea, M.H.; Said, A.A. Identification of ISSR and RAPD markers linked to yield traits in bread wheat under normal and drought conditions. J. Gen. Eng. Biotech. 2015, 13, 243-252. [CrossRef] [PubMed]

30. Pharmawati, M.; Yan, G.; Finnegan, P.M. Molecular variation and fingerprinting of Leucadendron cultivars (Proteaceae) by ISSR markers. Ann. Bot. 2005, 95, 1163-1170. [CrossRef] [PubMed]

31. Nei, M. Genetic distance between populations. Am. Nat. 1972, 106, 283-292. [CrossRef]

32. Tamura, K.; Dudley, J.; Nei, M.; Kumar, S. MEGA 4: Molecular evolutionary genetics analysis (MEGA) software version 4.0. Mol. Biol. Evol. 2007, 24, 1596-1599. [CrossRef]

33. Peakall, R.O.D.; Smouse, P.E. GENALEX 6: Genetic analysis in Excel. Population genetic software for teaching and research. Mol. Ecol. Notes 2006, 6, 288-295. [CrossRef]

34. Nei, M.; Li, W.H. Mathematical model for studying genetic variation in terms of restriction endonucleases. Proc. Natl. Acad. Sci. USA 1979, 76, 5269-5273. [CrossRef]

35. Botstein, D.; White, R.L.; Skolnick, M.; Davis, R.W. Construction of a genetic linkage map in man using restriction fragment length polymorphisms. Am. J. Hum. Genet. 1980, 32, 314.

36. Virk, P.S.; Ford-Lloyd, B.V.; Jackson, M.T.; Pooni, H.S.; Clemeno, T.P.; Newbury, H.J. Predicting quantitative variation within rice germplasm using molecular markers. Heredity 1996, 76, 296-304. [CrossRef]

37. Khadivi-Khub, A. Regression association analysis of fruit traits with molecular markers in cherries. Plant Syst. Evol. 2014, 300, 1163-1173. [CrossRef]

38. Kar, P.K.; Srivastava, P.P.; Awasthi, A.K.; Urs, S.R. Genetic variability and association of ISSR markers with some biochemical traits in mulberry (Morus spp.) genetic resources available in India. Tree Genet. Genomes 2008, 4, 75-83. [CrossRef]

39. Ganopoulos, I.V.; Kazantzis, K.; Chatzicharisis, I.; Karayiannis, I.; Tsaftaris, A.S. Genetic diversity, structure and fruit trait associations in Greek sweet cherry cultivars using microsatellite based (SSR/ISSR) and morpho-physiological markers. Euphytica 2011, 181, 237-251. [CrossRef]

40. Pignatti, G.; Crobeddu, S. Effects of rejuvenation on cutting propagation of Mediterranean shrub species. Forest@-J. Silvic. Forest Ecol. 2005, 2, 290. [CrossRef]

41. Isfendiyaroglu, M. Effects of some physical and biochemical factors on the rooting of mastic tree (Pistacia lentiscus var. chia Duham.) cuttings. J. Agric. Fac. Ege Univ. 2003, 40, 25-32.

42. Baskin, C.C.; Baskin, J.M. Seeds: Ecology, Biogeography, and Evolution of Dormancy and Germination; Academic Press: Cambridge, MA, USA, 1998; p. 666.

43. Pipinis, E.; Milios, E.; Tomazos, N.; Smiris, P. Breaking dormancy and germination of Cotinus coggygria Scop. seeds by means of sulphuric acid scarification, cold stratification and gibberellic acid. Silva Balcanica 2014, 15, 38-46.

44. Pipinis, E.; Milios, E.; Aslanidou, M.; Mavrokordopoulou, O.; Efthymiou, E.; Smiris, P. Effects of sulphuric acid scarification, cold stratification and plant growth regulators on the germination of Rhus coriaria L. seeds. J. Environ. Prot. Ecol. 2017, 18, 544-552. 